\title{
Cambio tecnológico y oportunidades de desarrollo como blanco móvil
}

\section{Carlota Pérez}

Investigadora Honoraria, SPRU, Universidad de Sussex. Investigadora Senior Adjunta, INTECH, Universidad de las Naciones Unidas,

Países Bajos

carperez@reacciun.ve
Este artículo propone una interpretación del desarrollo como proceso de acumulación de capacidades tecnológicas y sociales, en función del aprovechamiento de ventanas de oportunidad sucesivas y distintas. Estas vendrían determinadas, desde los países centrales, por las revoluciones tecnológicas que ocurren cada medio siglo y las cuatro fases que caracterizan su despliegue. Las posibilidades de avanzar en cada oportunidad dependerían de los logros de la fase anterior, la identificación de la naturaleza de la siguiente, la comprensión del paradigma tecnoeconómico que acompaña la revolución en cuestión y la habilidad para diseñar y negociar, en cada caso, una estrategia de suma positiva reconociendo las estrategias de las empresas más poderosas. Con esta interpretación se revisan someramente las sucesivas estrategias de desarrollo aplicadas desde la década de 1950. Luego se atisba el carácter de la próxima fase y, aplicando los principios del paradigma tecnoeconómico, se exploran algunos aspectos del cambio institucional por realizar. 


\section{I}

\section{Cambio tecnológico y desarrollo}

La tecnología suele concebirse como un campo especializado de la política de desarrollo, con instituciones separadas. No obstante, en el presente trabajo sostenemos que la tecnología, más que un elemento de las estrategias de desarrollo, es condición de su viabilidad. Las oportunidades de desarrollo son un blanco móvil. Cualquier observador serio del progreso alcanzado en materia de desarrollo desde fines de los años cincuenta hasta fines del decenio de 1970 tendrá que reconocer que las estrategias de sustitución de importaciones aplicadas por los diversos países se tradujeron en avances graduales y significativos. A mediados del decenio de 1970, cuando la combinación del redespliegue industrial del Norte con la promoción de exportaciones desde el Sur mostraba y prometía nuevos y más amplios avances, se tenía la esperanza de que el progreso sería constante. Con el fracaso y deterioro subsiguiente del modelo de protección y subsidios en la mayoría de los países que lo trataron de seguir aplicando, el péndulo se ha desplazado al otro extremo, negándose todos los logros conseguidos con ese modelo. Se abonó así el terreno para defender al libre mercado como la única forma de lograr resultados satisfactorios en materia de desarrollo, aunque la eficacia de esa política no se haya comprobado todavía.

Se sostiene en este artículo que las oportunidades de desarrollo surgen y se modifican a medida que se despliegan las sucesivas revoluciones tecnológicas en los países avanzados. La transferencia de tecnología y de equipo productivo sólo se efectúa voluntariamente cuando promete beneficio mutuo. Las estrategias de sustitución de importaciones fueron exitosas porque constituían un juego de suma positiva para las industrias maduras del mundo desarrollado que hacían frente al agotamiento tecnológico y a la saturación de sus mercados. Al surgir la revolución informática estas condiciones cambiaron radicalmente y se abrieron otras opciones viables.

Sobre la base de esta interpretación se examinan aquí las estrategias de desarrollo desde un ángulo diferente, especialmente útil en relación con los desafíos del proceso de globalización y de la era de la información. En primer lugar se analiza la evolución de las tecnologías, a fin de comprender en qué condiciones se crean las oportunidades de desarrollo y determinar su naturaleza. Después se aborda el tema del desarrollo como forma de aprender a aprovechar esas oportunidades cambiantes. El tema se ilustra con una revisión de los sucesivos modelos de desarrollo aplicados en los últimos 50 años y con un examen de los desafíos que plantea la próxima etapa de concentración del poder en la economía mundial. Por último, se estudian algunas de las exigencias institucionales para hacer frente al nuevo "paradigma de redes flexibles".

\section{II}

\section{El ciclo del producto, el desarrollo y el cambio en las barreras de ingreso}

El papel de la tecnología importada como tramo obligado del camino hacia la industrialización es hecho conocido históricamente por la experiencia de los Es-

$\square$ Este trabajo fue preparado originalmente para la UNCTAD x y presentado posteriormente en el seminario "La Teoría del Desarrollo en los Albores del Siglo XXI", organizado por la CEPAL en Santiago de Chile para conmemorar el centenario del nacimiento de Raúl Prebisch. tados Unidos y de varios países europeos en el siglo XIX y a principios del siglo XX. Más recientemente, han confirmado ese papel la rápida transformación del Japón en un país de primera línea y el gran avance en el desarrollo de los "cuatro tigres" del Asia. El éxito de estos países se ha debido, sin lugar a dudas, a la absorción de la tecnología de los países más avanzados y a sus propios esfuerzos para adoptar, adaptar, modificar y dominar los conocimientos técnicos co- 


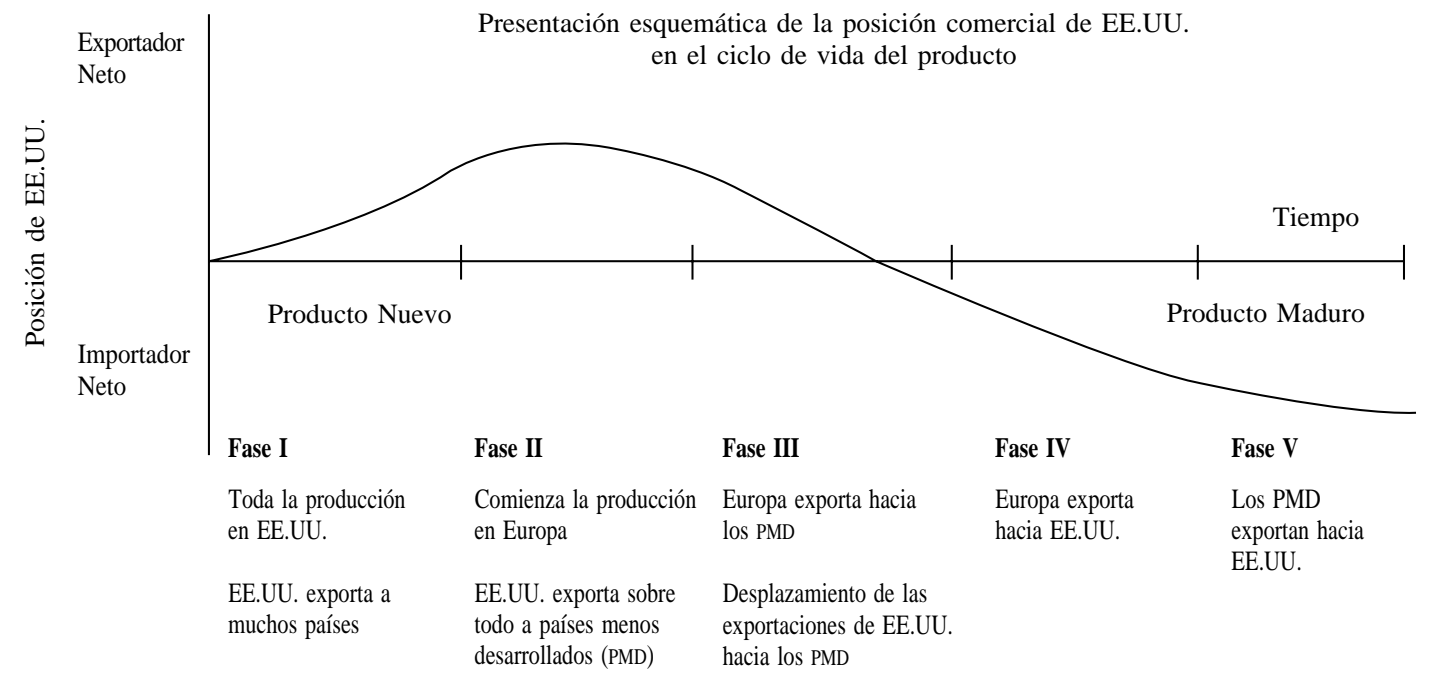

Fuente: Wells (1972), p. 15.

rrespondientes (Freeman, 1993; Amsden, 1989). Sin embargo, pueden citarse muchos más países que en ese mismo período tuvieron escaso éxito en promover el desarrollo, aunque aparentemente aplicaron procedimientos análogos para utilizar tecnología importada. Además, numerosos países y regiones enteras, como Africa y la mayor parte de Sudamérica, parecen haber perdido gran parte del terreno conquistado (Mytelka, 1989; Katz, ed., 1996).

Las causas de esos resultados tan distintos hay que buscarlas, en parte, en las políticas concretas aplicadas en cada caso y, en parte, en las condiciones particulares de cada país. A un nivel más profundo, esas causas están arraigadas en la naturaleza de las ventanas de oportunidad creadas por la evolución tecnológica de los países líderes y en la capacidad para aprovecharlas, consciente o intuitivamente. Ello hace necesario recurrir a la abundante literatura especializada sobre la forma cómo evolucionan y se difunden las tecnologías.

\section{El ciclo de vida del producto y la expansión geográfica de las tecnologías}

Uno de los primeros intentos de analizar las posibilidades tecnológicas de los países en desarrollo lo hizo Hirsch (1965). Examinando el comportamiento de la industria electrónica tradicional en función del ciclo del producto, Hirsch mostró cómo las ventajas se desplazaban a favor de los países menos adelantados cuando las tecnologías se aproximaban a su madurez. Wells
(1972) resumió gráficamente el proceso para el caso de los Estados Unidos, en su estudio de la bibliografía sobre el ciclo del producto (gráfico 1).

La migración de la producción desde el país de origen a otros países avanzados, y luego a los menos desarrollados, explicaría uno de los procesos observados por Leontief según el cual las exportaciones de los Estados Unidos tenían un mayor contenido de mano de obra que sus importaciones (Leontief, 1954). Esta situación, paradójica para el país líder en materia de tecnología, se relacionaba con las características cambiantes de las tecnologías en evolución. Las tecnologías tienden a hacer uso más intensivo de mano de obra durante sus fases iniciales y a utilizar personal relativamente costoso de alto conocimiento y calificación. ${ }^{1}$ En cambio, cuando se aproximan a la madurez, ya están utilizando procesos altamente estandarizados, mecanizados y automatizados.

Cuando las tecnologías maduran, hay fuerzas que las expulsan más y más hacia la periferia, donde, presumiblemente, hay fuerzas complementarias que las atraen para poner en marcha procesos de desarrollo. Aunque esta observación se aplica sobre todo a los bienes de consumo y a algunos bienes básicos de capital, la gama es suficientemente amplia para servir de punto de partida del análisis.

\footnotetext{
${ }^{1}$ Véanse Hirsch (1965 y 1967), Vernon (1966) y, de fecha reciente, Von Tunzelmann y Anderson (1999).
} 


\section{Con tecnologías maduras no puede haber sal- tos en el desarrollo ${ }^{2}$}

Es irónico que las ventajas se desplacen a favor de los países con recursos financieros escasos precisamente cuando el proceso de producción se caracteriza por un uso más intensivo del capital. Al llegar a esa fase, las tareas se han hecho tan rutinarias —véanse las fases 4 del gráfico $2-3$ que los gerentes no necesitan gran conocimiento previo ni mucha experiencia, y los procesos pueden emplear mano de obra no calificada. Por otra parte, a medida que la tecnología y los mercados alcanzan la madurez, la ventaja determinante es el perfil de costos comparativos.

¿Puede haber un verdadero salto en el desarrollo basado en tecnologías maduras? Es sumamente difícil y ello por varias razones. Como se indica en el gráfico 3, las tecnologías maduras llegan a un punto en el que tienen un potencial mínimo para producir beneficios, enfrentan mercados estancados y casi no les queda campo para mejorar la productividad. Así pues, en general, la fase de madurez como punto de partida es costosa, y no es muy rentable ni muy prometedora. Con todo, se trata probablemente del mejor punto de partida para crear una plataforma básica de industrialización, generar capacidad de aprendizaje y establecer la infraestructura básica y otros factores externos requeridos para respaldar un esfuerzo de desarrollo.

Sin embargo, alcanzar el desarrollo supone un proceso dinámico, alimentado por innovaciones locales y mercados crecientes, por lo cual habría que ingresar tan temprano como fuera posible. Aunque parezca extraño, aparte de la fase de madurez, el otro momento cuando los actores débiles enfrentan obstáculos superables no es en la segunda ni en la tercera

GRAFICO 2

Cambio en los requisitos de ingreso según la fase de evolución de las tecnologías

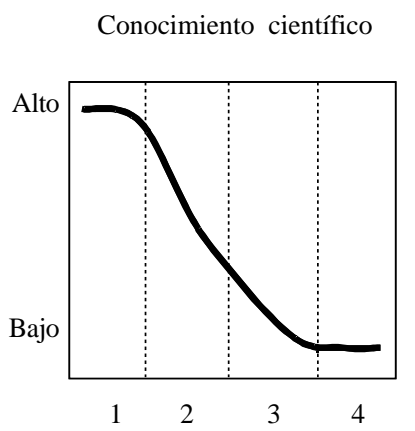

Experiencia y know-how

Capacidad para usar mano de

Importancia relativa de las obra no calificada ventajas de ubicación
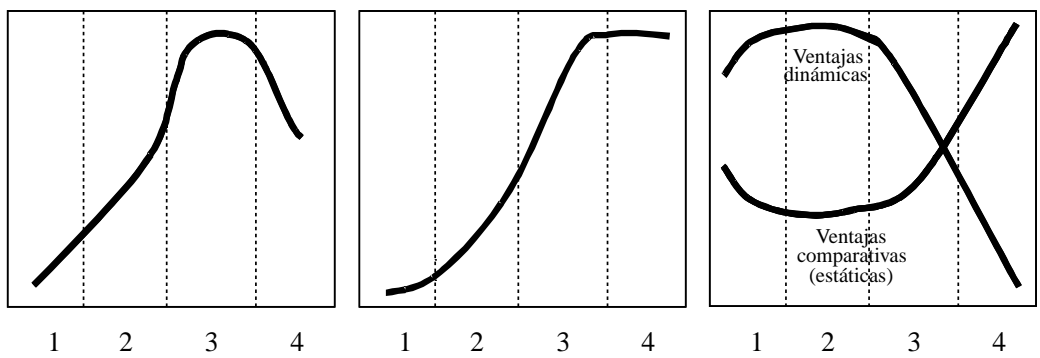

Fuente: Basado en Pérez y Soete (1988) y Hirsch (1967).

GRAFICO 3

Cambio en el potencial de las tecnologías según la fase de evolución
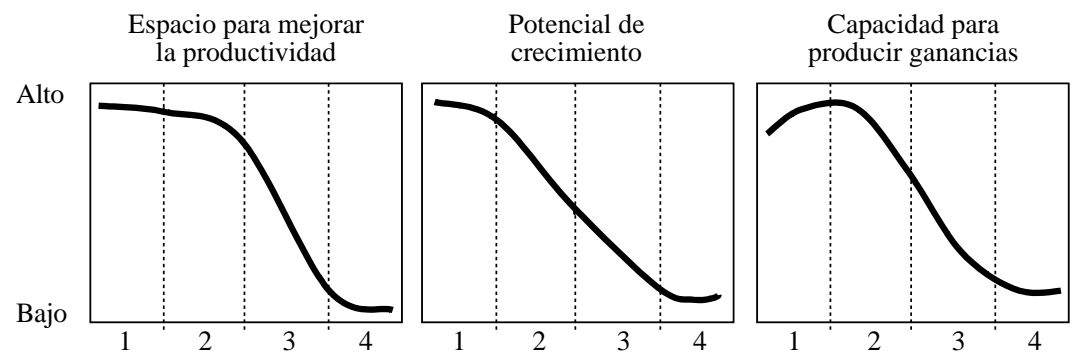

Costo de la inversión (en equipamiento)

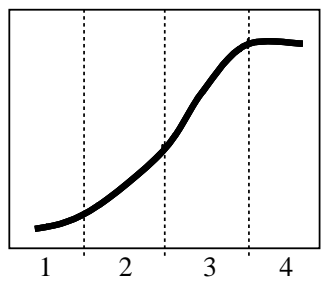

Fuente: Basado en Gerschenkron (1962), Cundiff y otros (1973), Kotler (1980) y Dosi (1982).

\footnotetext{
${ }^{2}$ Este apartado se basa en Pérez y Soete (1988).
}

\footnotetext{
${ }^{3}$ Puede considerarse que la cuarta fase abarca aproximadamente las fases IV y V del diagrama de Wells (véase el gráfico 1).
} 
fase, sino en la primera. Este resulta ser el punto de ingreso más prometedor, ya que, como se indica en el gráfico 3 , son grandes las posibles ganancias, se presentan amplias posibilidades de crecimiento del mercado y la productividad y los costos de inversión son relativamente bajos. Incluso la inversión en actividades de investigación y desarrollo puede con frecuencia ser menor que la del innovador original.

Cabría entonces pensar que solamente las empresas de países avanzados poseerían el alto grado de conocimientos requerido en esta fase (véase el gráfico 2). No obstante si los productos nuevos forman parte de las primeras fases de una revolución tecnológica, los conocimientos involucrados tienden a ser de dominio público (disponibles en las universidades, por ejemplo). Como ilustración baste citar el caso reciente de Silicon Valley y sus millares de imitadores exitosos en el mundo. En esos casos no es muy grande la experiencia previa requerida, y poseerla podría incluso ser una desventaja, porque las revoluciones tecnológicas implantan nuevos modelos de gestión que hacen obsoletos los anteriores.
El otro factor restrictivo se relaciona con el medio circundante. El éxito con tecnologías nuevas depende de ciertos factores complementarios importantes como las ventajas dinámicas y externalidades de diverso tipo, especialmente las infraestructuras física, social y tecnológica, o la existencia de clientes locales competentes y exigentes. Estos elementos pueden haberse creado antes con tecnologías maduras, o adquirirse mediante intensos procesos de aprendizaje e invirtiendo en el mejoramiento del medio social y económico.

Parecería entonces que se podría diseñar una estrategia para acumular capacidad tecnológica y social usando tecnologías maduras y luego aprovechar esa base para acceder a tecnologías nuevas y dinámicas, pero esa posibilidad depende en alto grado de las oportunidades específicas creadas por las sucesivas revoluciones tecnológicas. Comprender cabalmente la evolución de las tecnologías en los países avanzados puede ser provechoso para los países en desarrollo que deseen diseñar estrategias viables. Este es el tema de la sección siguiente.

\section{III}

\section{Tecnologías, sistemas, revoluciones}

\section{y paradigmas}

La evolución tecnológica es un proceso complejo; las tecnologías se interconectan en sistemas y éstos, a su vez, se entretejen y son interdependientes, tanto entre sí como en relación con el entorno físico, social e institucional.

Gran parte del aprendizaje tecnológico es gradual e incremental. Sin embargo, no hay ninguna progresión inevitable hacia una frontera cada vez más lejana y siempre inalcanzable; existen importantes discontinuidades que se convierten en ventanas por las que los recién llegados pueden saltar adelante. Estas oportunidades se dan en forma de revoluciones tecnológicas e implican fuertes cambios de dirección en el avance tecnológico; también proporcionan los medios para modernizar la mayoría de las actividades a costa de abandonar muchos de los conocimientos de gestión acumulados anteriormente y parte del equipamiento anterior, junto con los conocimientos especializados conexos. Las nuevas tecnologías de carácter revolucionario abren oportunidades inéditas para aprender y alcanzar el desarrollo. La interacción de los cambios tecnológicos continuos y discontinuos explica por qué y cómo varían las oportunidades de desarrollo con el tiempo.

\section{Las trayectorias tecnológicas y la acumulación de experiencia}

Pese a sus variaciones específicas, gran parte de las tecnologías tiende a seguir una trayectoria similar en cuanto al ritmo y la dirección del cambio y las mejoras — desde la innovación inicial hasta la madurez-, evolución que coincide aproximadamente con la de sus mercados: desde la introducción hasta la saturación ${ }^{4}$ (gráfico 4).

\footnotetext{
4 Abernathy y Utterback (1975), Dosi (1982) y Sahal (1985). Entre los libros de texto sobre la gestión de negocios cabe señalar a Cundiff y otros (1973) y Kotler (1980). Una sinopsis amplia aparece en Coombs y otros (1987) y Dosi (1988). La interpretación completa de las relaciones entre la tecnología, la economía y las políticas figura en la obra clásica de Freeman (1974) acerca de la economía de la innovación, y en la versión actualizada de Freeman y Soete (1997).
} 
GRAFICO 4

La evolución de una tecnología: Una trayectoria tecnológica

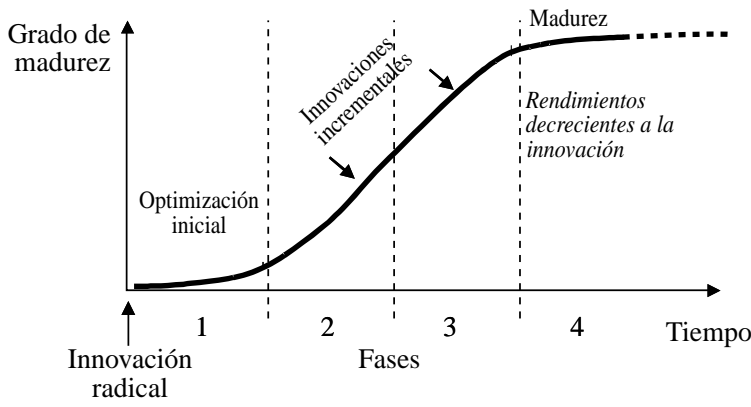

Fuente: Basado Nelson y Winter (1977), Dosi (1982), Freeman y Pérez (1988), Wolf (1912), Abernathy y Utterbak (1975) y otros autores.

Luego que una innovación radical da lugar a la aparición de un nuevo producto, capaz de sustentar el desarrollo de una nueva industria, hay un período inicial de intensa innovación y optimización, hasta lograr la aceptación del producto en el segmento correspondiente del mercado. La interacción con el mercado pronto determina la dirección de las mejoras, que a menudo definen un diseño dominante (Arthur, 1989; David, 1985). Desde ese punto, y a medida que crecen los mercados, se registran innovaciones incrementales sucesivas para mejorar la calidad del producto, la productividad del proceso y la situación de los productores en el mercado. Se culmina en la madurez cuando la nueva inversión en innovaciones tiene rendimientos decrecientes. Según la importancia que tenga el producto, todo el proceso puede durar unos pocos años o varios decenios. En este último caso, las "mejoras" suelen ser modelos sucesivos.

Tras las primeras innovaciones, los que están desarrollando la tecnología adquieren ventajas, no sólo mediante patentes sino también —lo que quizás sea más importante - gracias a la experiencia acumulada con el producto, el proceso y los mercados. Ello tiende a encerrar los correspondientes conocimientos generales y especializados dentro de las empresas y sus proveedores, haciéndolos cada vez más inaccesibles a nuevos participantes. Esa experiencia, además, acelera la adopción de las innovaciones subsiguientes, por lo que las más recientes son incorporadas rápidamente y es aun más difícil para los rezagados alcanzar a los punteros (véase el gráfico 5, que muestra este fenómeno tomando como ejemplo el caso de innovaciones sucesivas en el automóvil).
GRAFICO 5

Acortamiento del ciclo de las innovaciones tardías: La difusión de las tecnologías sucesivas en la industria automotriz de los Estados Unidos

Porcentaje de la producción que incorpora la innovación

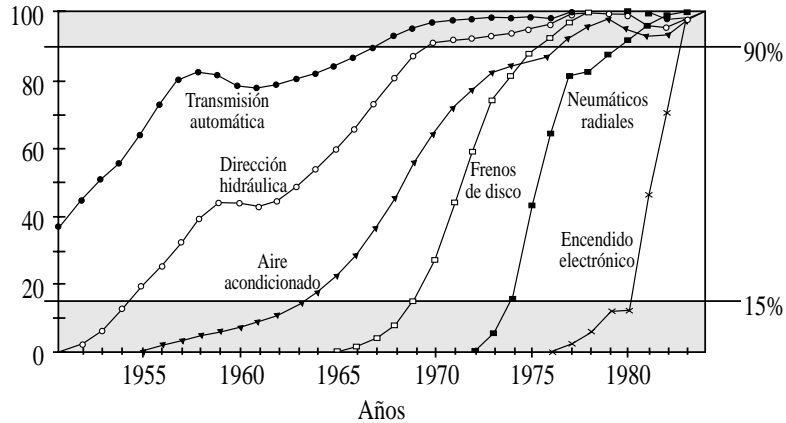

Fuente: Jutila y Jutila (1986), citado en Grübler (1990, p. 155).

\section{Los sistemas tecnológicos y la creación de capacidad social}

Las tecnologías no se desarrollan en forma aislada sino conectadas unas con otras, en sistemas, apoyándose recíprocamente y aprovechando la experiencia, el desarrollo de proveedores, la educación de los consumidores y otras externalidades creadas por sus antecesores en el sistema (Freeman, Clark y Soete, 1982).

La evolución de los sistemas tecnológicos sigue una trayectoria análoga a la de los productos individuales (gráfico 4). Los nuevos productos representan las mejoras incrementales del sistema. En las dos primeras fases hay muchos productos realmente importantes con un largo ciclo de vida; después, tienden a disminuir en número e importancia, hasta que los últimos son poco significativos y tienen un ciclo de vida breve (como los neumáticos radiales y el encendido electrónico en el gráfico 5).

En el gráfico 6 se presenta un ejemplo estilizado del sistema tecnológico de los aparatos electrodomésticos, que comienza con los refrigeradores, las lavadoras y las aspiradoras, y se amplía después con una serie de nuevos productos y modelos sucesivos de los primeros. Los unos y los otros suelen llegar a la madurez de manera más o menos simultánea junto con la introducción de las últimas innovaciones menores del sistema, como los abrelatas y cuchillos eléctricos. En el gráfico se indica también la forma en que los sistemas se arraigan en determinados territorios gracias a la extensión de la red de proveedores de repuestos y al 


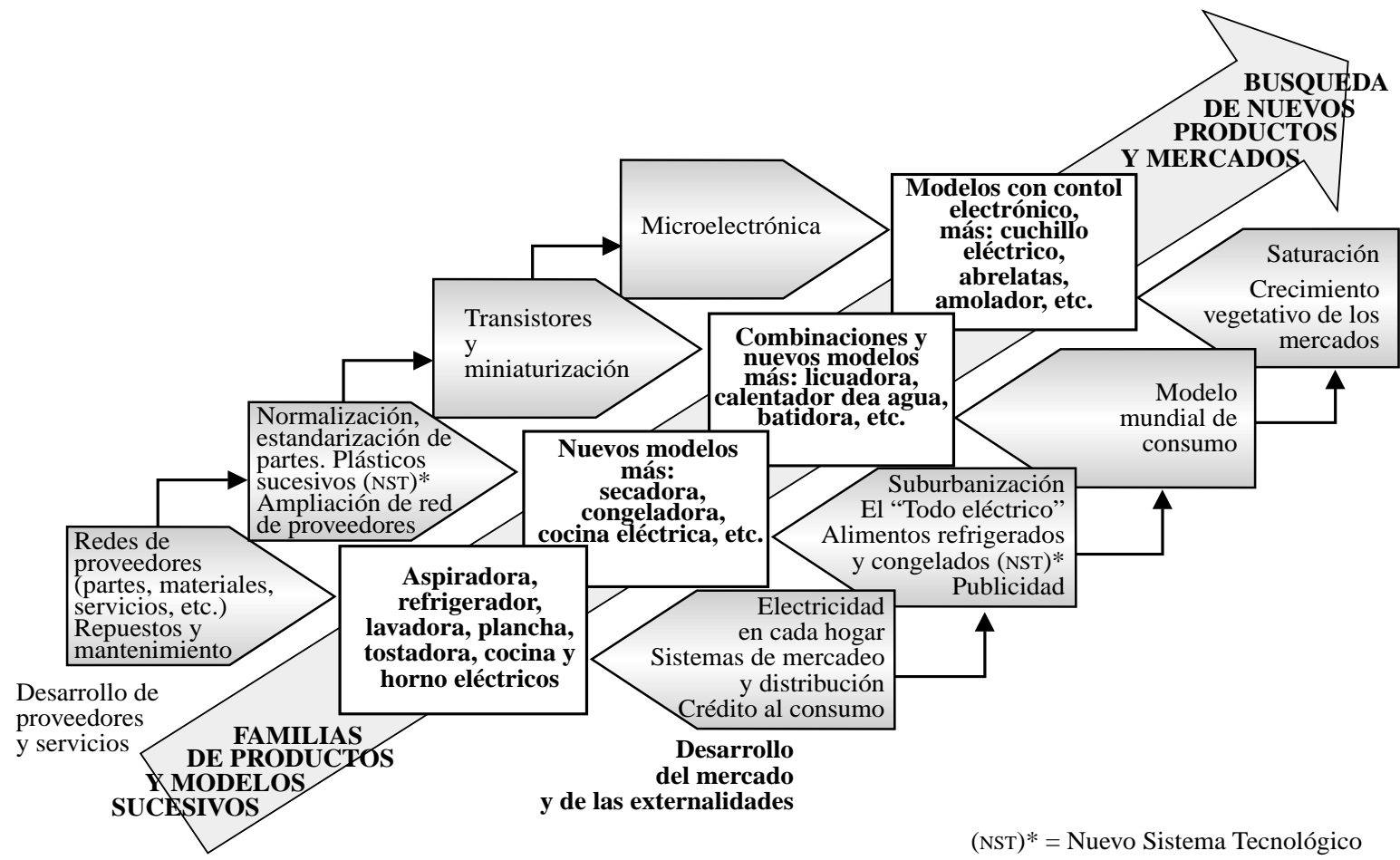

establecimiento gradual del marco regulatorio y otros elementos de facilitación institucional.

Esta creciente interacción de elementos "duros y blandos" es uno de los aspectos a que se refería Abramovitz (1986), cuando criticaba el concepto de desarrollo como la simple acumulación de capital y trabajo y subrayaba la necesidad de adquirir capacidad social. Esa interacción también se vincula con la noción de sistemas de innovación nacionales o regionales, creados por los agentes que interactúan en el proceso (Freeman, 1993; Lundvall, 1988 y 1992).

La necesidad de formar estas complejas redes de actividades e instituciones que se apoyan recíprocamente explica algunas de las limitaciones a que hace frente el desarrollo cuando se basa en la transferencia de tecnologías maduras. También apoya el argumento de quienes recomiendan aprovechar las tradiciones, la capacidad local y los conocimientos existentes en cada territorio concreto (Porter, 1991). Por último, muestra el tipo de acciones que serían necesarias para apoyar en forma eficaz la supervivencia de empresas de vanguardia en los países en desarrollo.

\section{Las revoluciones tecnológicas y la interco- nexión de los sistemas ${ }^{5}$}

Cada revolución tecnológica es un conjunto de sistemas tecnológicos que gradualmente crean las condiciones necesarias para la aparición de nuevos sistemas, todos los cuales siguen principios similares y cuentan con los mismos factores externos. En los gráficos 7 y 8 se ilustran dos de esas explosiones de nuevas tecnologías: la revolución de la producción en serie con sus sistemas sucesivos, que cristalizó alrededor de 1910 y llegó a su madurez en los años sesenta y setenta, y la revolución informática, que se ha venido difundiendo desde los años setenta.

El proceso de multiplicación de innovaciones y sistemas tecnológicos, aguas arriba y aguas abajo de las industrias que forman el núcleo de cada revolución tecnológica, explica el enorme potencial de crecimiento que tiene cada una de estas constelaciones de nuevas

\footnotetext{
${ }^{5}$ Freeman y Pérez (1988). Un análisis exhaustivo de cada una de las revoluciones, desde la revolución industrial en Inglaterra, se encuentra en Freeman y Louçã (2001).
} 
La revolución de la producción en serie: Una red creciente de sistemas tecnológicos desplegándose desde 1910

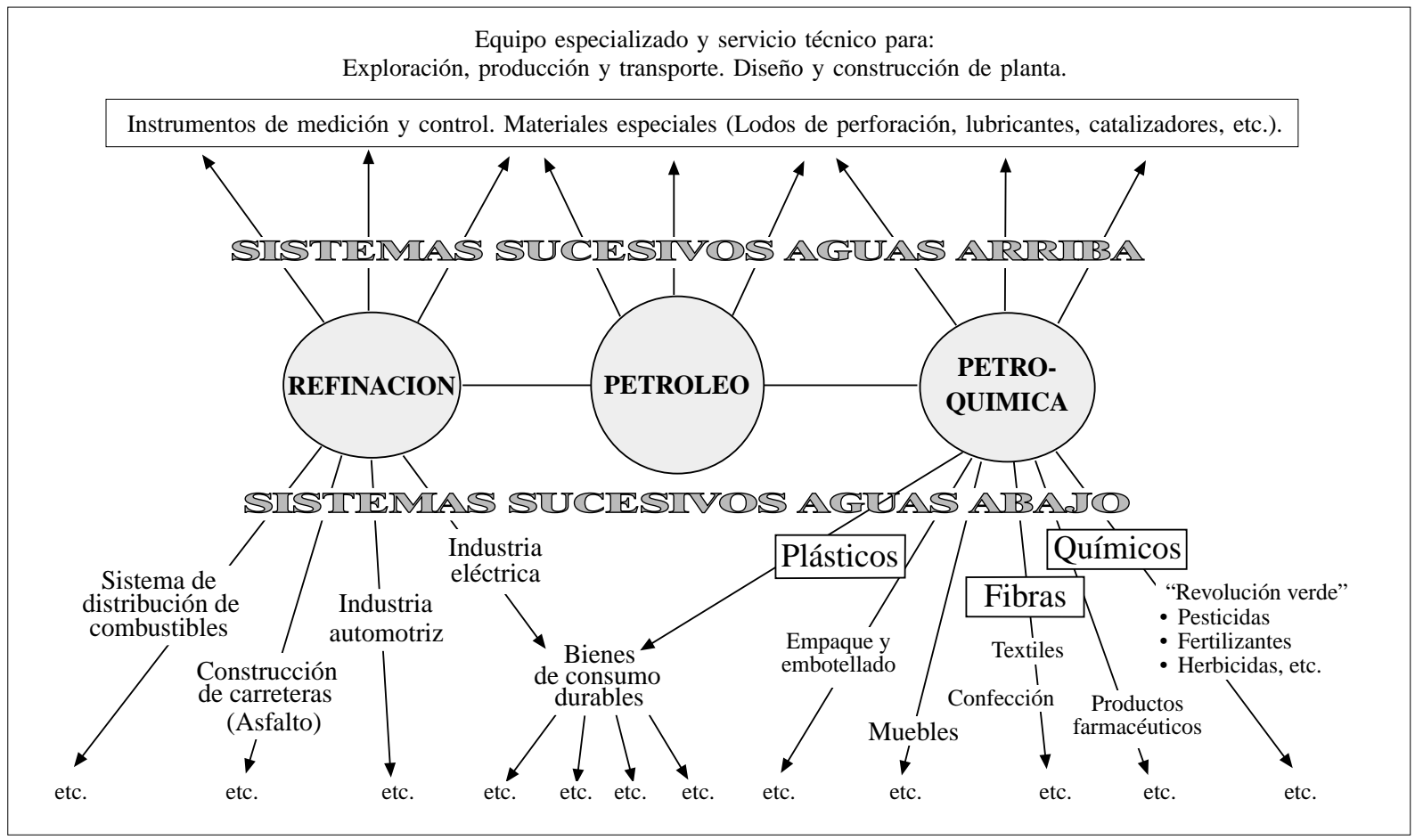

GRAFICO 8

La revolución informática: Una red creciente de sistemas tecnológicos desplegándose desde 1970

Equipos especiales, provisión de partes, servicios especializados, nuevos materiales, satélites. Fibra óptica, firmware y software especializados, ciencia de vanguardia, etc.
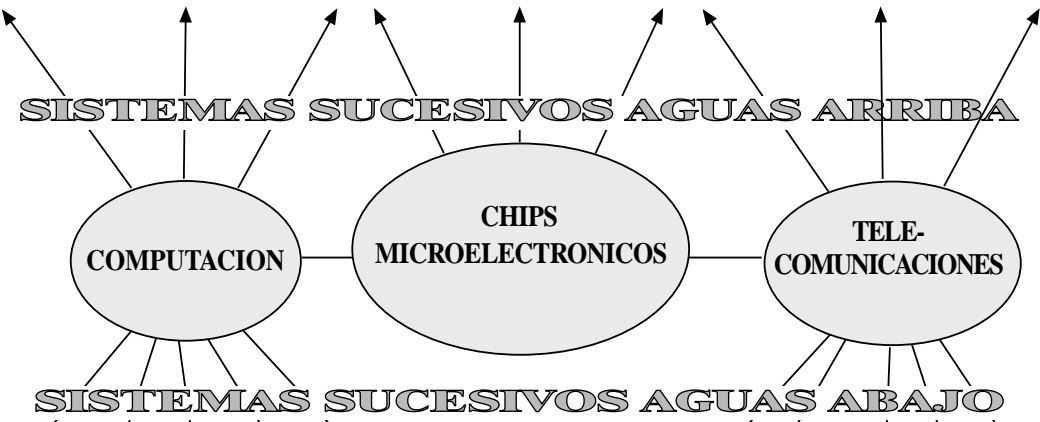

Equipos para servicios

especializados

- Medicina

- Laboratorios

- Espacial

- Militar

- etc.

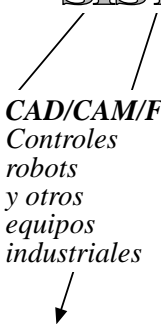

etc.

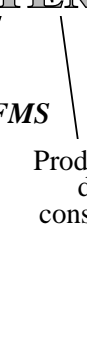

etc.

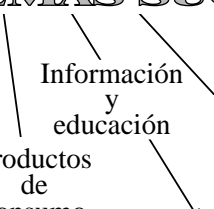

consumo

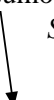

Productos personales y de oficina

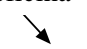

Software y múltiples usos de la Informática y las telecomunicaciones

etc.

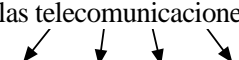

etc. etc. etc. etc.

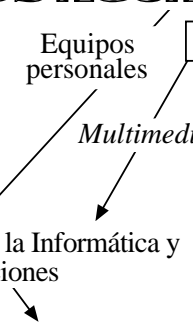

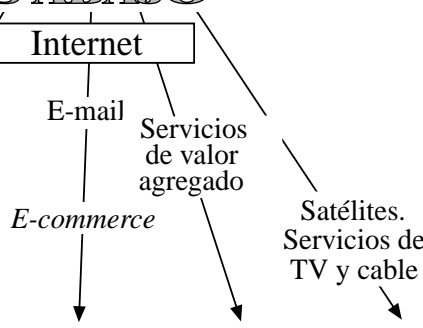

etc. etc. 
tecnologías. Se trata de la apertura de un nuevo y vasto territorio para la innovación, la expansión y el crecimiento. Las innovaciones iniciales marcan el "descubrimiento", mientras que la plena "ocupación" del territorio corresponde a la fase de madurez y agotamiento.

Los gráficos 4 y 5, proyectados en el tiempo, pueden leerse también como la trayectoria de vida de una revolución tecnológica. En este caso, las "mejoras" incrementales serían los nuevos sistemas tecnológicos sucesivos. Como en los casos anteriores, en el período temprano de crecimiento aparecen muchos sistemas importantes y, a medida que se avanza hacia la madurez, los nuevos sistemas tienden a disminuir, tanto en número como en envergadura.

\section{Paradigmas tecnoeconómicos y rejuveneci- miento de todas las actividades}

Las industrias maduras existentes ni se estancan ni cohabitan pasivamente con las nuevas industrias. Cada revolución tecnológica aporta tecnologías genéricas y ubicuas, así como nuevas prácticas de organización que dan lugar a un aumento significativo de la productividad potencial de la mayoría de las actividades existentes. Los principios en que se basa ese proceso modernizador se incorporan gradualmente a un modelo de práctica óptima que hemos denominado "estilo tecnológico" o "paradigma tecnoeconómico". 6 El resultado es un rejuvenecimiento gradual de toda la estructura productiva, de modo que las industrias maduras actualizadas puedan volver a comportarse como industrias nuevas, en cuanto a dinamismo, productividad y rentabilidad.

Este proceso podría explicar la decepción de quienes, en el Diálogo Norte-Sur de los años setenta, abrigaban la esperanza de trasladar las industrias maduras al mundo en desarrollo en forma permanente. Desde los años ochenta se ha modernizado una industria tras otra; incluso una industria tan tradicional como la confección ha sido rejuvenecida y puesta en una senda innovadora, con mercados segmentados (Hoffman y Rush,1988; Mytelka,1991).

\section{El cambio de paradigma como cambio del sen- tido común gerencial}

Un paradigma tecnoeconómico articula los modelos técnico y organizativo para aprovechar al máximo el potencial de la revolución tecnológica correspondiente. Cada paradigma proporciona un nuevo conjunto de principios de "sentido común" que sirven para orientar la toma de decisiones de empresarios, innovadores, gerentes, administradores, ingenieros e inversionistas hacia la máxima eficiencia y eficacia, tanto en las actividades nuevas como en las viejas. Para quienes habían obtenido resultados satisfactorios con el paradigma anterior, el proceso de adopción de uno nuevo puede resultar devastador. Además de exigir el abandono de una experiencia adquirida con gran esfuerzo, es como si el mundo se parara de cabeza (Peters,1989; Coriat,1991).

El gráfico 9 muestra cómo, con el paso del paradigma de la producción en serie al modelo de redes flexibles, se transforman los criterios de gestión en todos los campos, desde la selección y diseño del producto a las estructuras organizacionales; los modos de funcionamiento y las relaciones con el personal.

Fenómenos como la globalización y la tendencia hacia la descentralización política también guardan estrecha relación con el cambio de paradigma, con las nuevas posibilidades que ofrece y con la manera más eficaz de aprovecharlas. Puede considerarse que la descripción schumpeteriana de las revoluciones tecnológicas como procesos de "destrucción creadora" no se aplica sólo a la economía sino también a las políticas y las instituciones. ${ }^{7}$

El proceso de transformación no es fácil; la transición a las nuevas prácticas puede demorar dos o tres décadas. A la larga, el nuevo paradigma se convierte en el sentido común general y se considera como el estado natural y normal.

Los recién llegados, es decir, los que no han tenido una experiencia exitosa con el paradigma anterior, pueden reorientar sus esfuerzos hacia el aprendizaje de las nuevas prácticas, mientras los líderes establecidos tienen que "desaprender" gran parte del viejo paradigma y adoptar el nuevo. Mucha de la experiencia adquirida y una cantidad considerable de las inversiones realizadas en el contexto anterior se vuelven obsoletas

\footnotetext{
${ }^{7}$ Las empresas del mundo en desarrollo han tenido que vivir una doble transición al tener que renunciar al modelo proteccionista

(véase Pérez, 1996).
}

\footnotetext{
${ }^{6}$ Pérez (1983 y 1986). La expresión toma la noción de paradigma tecnológico propuesta por Dosi (1982) para describir las trayectorias de las distintas tecnologías, y la engloba en un concepto más amplio que define una trayectoria común "metaparadigma".
} 


\section{Cambio de Paradigma}

MODELO DE PRODUCCION EN SERIE Epoca del petróleo y el automóvil

\begin{tabular}{|c|c|}
\hline $\begin{array}{l}\text { Insumos } \\
\text { y valor }\end{array}$ & $\begin{array}{l}\text { Uso intensivo de energía y materias } \\
\text { primas en productos, procesos, } \\
\text { transporte, etc. } \\
\text { Productos tangibles }\end{array}$ \\
\hline $\begin{array}{l}\text { Productos y } \\
\text { mercados }\end{array}$ & $\begin{array}{l}\text { Productos estandarizados } \\
\text { Mercados masivos }\end{array}$ \\
\hline $\begin{array}{l}\text { Modo de } \\
\text { operar }\end{array}$ & $\begin{array}{l}\text { One best way } \\
\text { La rutina óptima es la meta }\end{array}$ \\
\hline Estructuras & $\begin{array}{l}\text { Organizaciones centralizadas } \\
\text { Pirámides jerárquicas } \\
\text { Departamentos funcionales } \\
\text { Canales rígidos de comunicación }\end{array}$ \\
\hline Personal & $\begin{array}{l}\text { Recursos humanos } \\
\text { La mano de obra como costo } \\
\text { El entrenamiento como una externalidad } \\
\text { esperada }\end{array}$ \\
\hline
\end{tabular}

MODELO DE REDES FLEXIBLES

Epoca de la tecnología informática

Uso intensivo de información y

conocimiento

Ahorro de energía y materias primas

Servicios y valor intangible
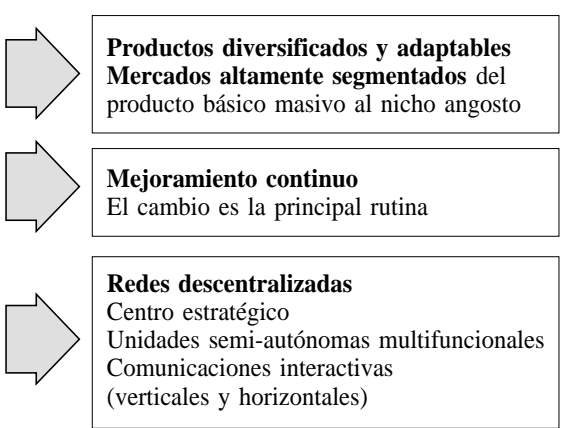

Capital humano

La mano de obra como activo

El entrenamiento como inversión

Un cambio en el "sentido común” tecnológico y gerencial

y tienen que ser reemplazadas. El proceso de renovación es largo y difícil, por lo que los recién llegados tienen cierta ventaja, la que puede ser respaldada con inversiones tempranas en la nueva infraestructura y la creación de instituciones adecuadas para facilitar el proceso.

\section{IV}

\section{El desarrollo como proceso de aprender a aprovechar oportunidades cambiantes}

El cuadro trazado a grandes rasgos caracteriza la evolución tecnológica como un proceso con períodos de continuidad y discontinuidad enraizados en la naturaleza de la competencia en el sistema capitalista. A nivel microeconómico, cada una de las innovaciones radicales representa una discontinuidad seguida por una evolución constante, hasta que la reducción de las posibilidades de aumentar la productividad y los beneficios impulsa la búsqueda de otras innovaciones radicales. A escala macrosistémica las revoluciones tecnológicas sucesivas irrumpen en el sistema económico, trayendo consigo constelaciones de nuevos productos, tecnologías e industrias. Estas discontinuidades funda- mentales inducen grandes oleadas de crecimiento, al principio en el núcleo de los países industrializados, donde además de la expansión explosiva de las industrias nuevas abarcan y rejuvenecen gradualmente a la mayoría de las industrias existentes. Al final, cuando el conjunto se acerca a la madurez, el proceso se difunde hacia la periferia, mientras que en los países centrales se está gestando ya la próxima gran oleada innovadora.

Los países en desarrollo persiguen, pues, un blanco móvil, que no sólo avanza constantemente, sino que también cambia de dirección aproximadamente cada medio siglo. Si se descarta la autarquía como opción, 
el desarrollo es cuestión de aprender a practicar este juego de desplazamiento y variación constantes, que es también un juego de poder.

¿Sería ésta otra versión de la teoría de la dependencia? Es indudable que implica una noción de complementariedad norte-sur y centro-periferia; al mismo tiempo, ofrece, sin embargo, la posibilidad de romper el círculo vicioso del subdesarrollo mediante la adopción de políticas apropiadas. Quienes entiendan el juego y lo jueguen bien podrían encontrar la forma de dar un salto adelante y alcanzar el desarrollo. Las verdaderas lecciones que enseñan los tigres asiáticos no radican en recetas repetibles sino en la comprensión de la dinámica específica que hizo posible el desarrollo, principalmente el hecho de que las condiciones más favorables para avanzar se dan durante los períodos de cambio del paradigma.

\section{Las transiciones de paradigma como doble oportunidad tecnológica}

Durante un período de unos 20 años o más, durante la transición de un paradigma a otro, coexisten las tecnologías viejas con las nuevas. El grueso de las tecnologías maduras del paradigma anterior se va estirando al máximo, intentando superar la limitación al crecimiento de su productividad y de sus mercados desplegándose geográficamente para sobrevivir. Esto ocurre al tiempo que las nuevas tecnologías se expanden, florecen y crecen rápidamente y con grandes márgenes de beneficio. Eso caracterizó los decenios de los setenta y los ochenta en los países desarrollados, dando lugar a tendencias centrífugas, en que los ricos, los modernos y los exitosos se hacen más ricos, y los pobres y débiles se empobrecen más. Sin embargo, y paradójicamente, en este período, de las peores condiciones sociales y económicas, aparecen las mejores oportunidades.

Durante la transición entre paradigmas se abren simultáneamente las dos mayores ventanas de oportunidad: la fase uno, de las nuevas tecnologías, y la fase cuatro, de las maduras (gráfico 10).

Aunque los productos maduros pueden servir para lograr el crecimiento durante cierto tiempo, no son capaces de propulsar un proceso de avance acelerado del desarrollo, porque su potencial de innovación está en buena medida agotado. Sin embargo, durante las transiciones de paradigma se abre una excelente oportunidad para dar un salto adelante. Las nuevas tecnologías genéricas y los principios de organización pueden aplicarse para modernizar y rejuvenecer las tecnologías maduras (e incluso las tecnologías tradicionales), como ocurrió, por ejemplo, en el sector del automóvil y en otras industrias en Japón, las industrias de la construcción naval y el acero en la República de Corea, los instrumentos quirúrgicos en Pakistán (Nadvi,1999), las

GRAFICO 10

La transición como la mejor oportunidad para dar un salto adelante

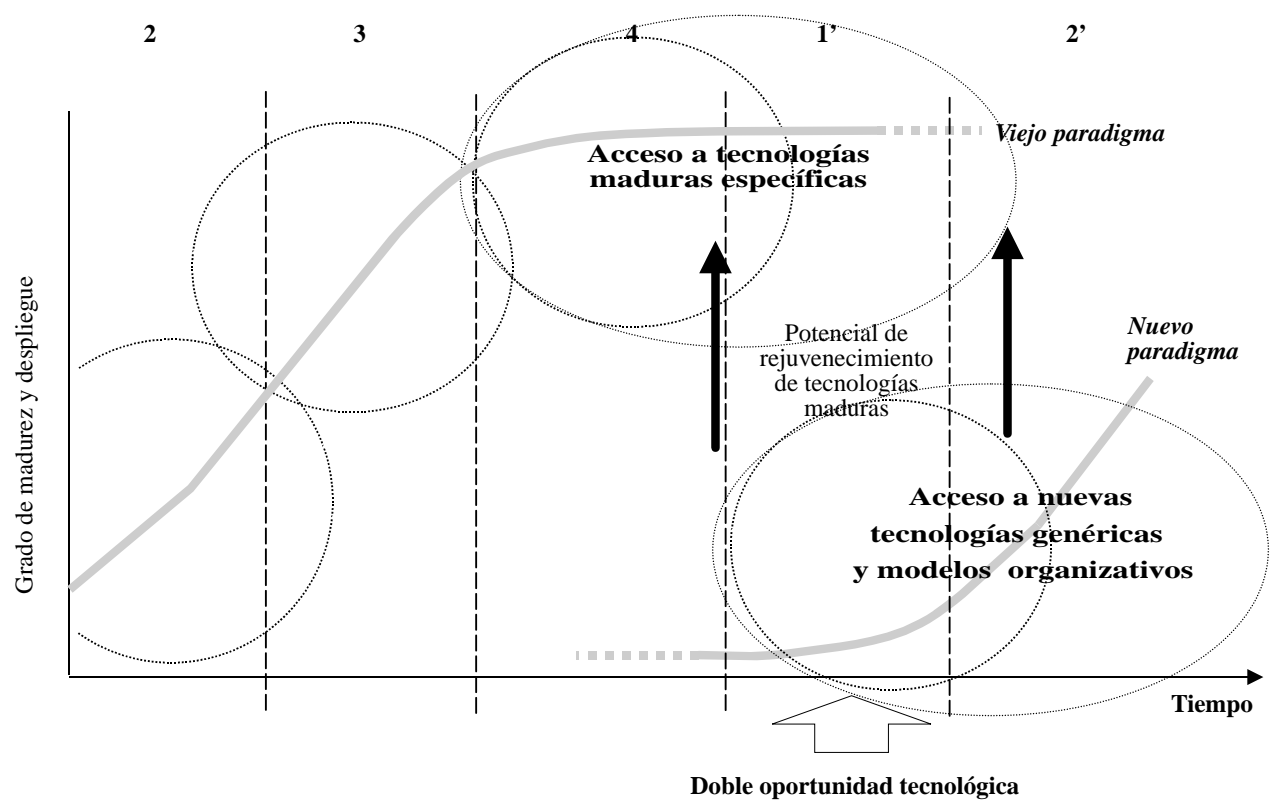

CAMBIO TECNOLOGICO Y OPORTUNIDADES DE DESARROLLO COMO BLANCO MOVIL • CARLOTA PEREZ 
exportaciones de flores frescas de Colombia y las de salmón fresco de Chile. ${ }^{8}$ Durante la transición, también es posible tratar de ingresar directamente a las nuevas industrias, como lo hicieron muchas empresas del mundo en desarrollo con productos microelectrónicos y software. El problema radica luego en cómo atravesar exitosamente las fases dos y tres. Muchas de las brillantes estrellas tempranas desaparecieron en el intento. Mantenerse en la carrera exige creciente apoyo por parte del entorno, innovación constante, inversiones de uso intensivo de capital y, probablemente, una gran capacidad de maniobra en cuanto a mercados y alianzas. Los chips de memoria de la República de Corea, las unidades de disco de Singapur y los clones informáticos de Asia son ejemplos de ese tipo de éxito, aunque cada uno en condiciones muy específicas.

En la actual transición de paradigma surgió una tercera posibilidad muy importante en el contexto de la globalización. A diferencia de la forma cómo se desplegó el paradigma de la producción en serie, en el que las industrias primero conquistaron el mercado nacional y luego invadieron el internacional, muchas industrias del presente paradigma han funcionado en el plano mundial desde la primera fase. Ello ha abierto la posibilidad de participar en redes globales en diversos roles y con distintos tipos de arreglo (Hobday, 1995; Radosevic, 1999). También ha permitido producir localmente para exportar por conducto de redes globales de comercialización, ya sea como empresas independientes u organizando grupos cooperativos tipo "cluster". 9

\section{2. "Danzar con lobos"10 o la cuestión de las es- tructuras del poder}

Para comprender las condiciones de acceso a la tecnología en forma cabal es necesario considerar las estructuras del poder. La naturaleza cambiante de las barreras de ingreso guarda estrecha relación con los niveles y formas de competencia y de concentración en la industria de que se trate. La naturaleza de cada fase determina el comportamiento de las empresas interesadas y modifica gradualmente su principal foco de atención y sus intereses.

El cuadro 1 resume los cambios en los patrones de competencia y en las estructuras del poder, típicos

\footnotetext{
${ }^{8}$ Estos y otros ejemplos se describen en CEPAL (1990).

9 Schmitz y Knorringa (1999) y Schmitz y Nadvi (1999). Véase también IDS Collective Efficiency Research Project (2001).

${ }^{10}$ Utilizado con un sentido similar por Mytelka (1994).
}

de la evolución de las industrias, sus tecnologías y sus mercados. También indica la amplitud de la ventana de oportunidad existente en cada fase y las condiciones que deben cumplir empresas que aspiren a ingresar al sector, ya sea en forma dependiente (es decir, formando parte de la estrategia de las empresas propietarias), o de manera autónoma, entrando al mercado en competencia directa.

Este esquema estilizado no puede representar todos los casos, ni cae en el ámbito de este breve trabajo examinar todas las variaciones y sutilezas en juego. Sin embargo, el cuadro puede servir como marco de referencia para plantear algunas observaciones importantes:

i) Dado que siempre habrá productos e industrias pasando por las distintas fases, hay que estar consciente y mantenerse informado sobre la fase de evolución de las tecnologías específicas y de los patrones de competencia prevalecientes en los diversos segmentos de mercado, para poder identificar los intereses de posibles aliados o competidores y evaluar sus fortalezas. Este proceso será útil también para estimar el valor de los activos propios y las posibilidades de la empresa, con miras a mejorar el proceso de toma de decisiones y el diseño de la estrategia de negociación.

ii) También es importante identificar la fase de despliegue en que se encuentra la revolución tecnológica. Como las revoluciones implican la coevolución de muchos sistemas, durante las primeras décadas de despliegue de las mismas habrá muchas tecnologías nuevas importantes en las fases uno y dos, mientras que en las décadas posteriores tienden a predominar las tecnologías que se aproximan a las fases de madurez (tres y cuatro) hasta que se superponen con las del nuevo paradigma en la transición siguiente. Así pues, las ventanas de oportunidad de cada tecnología están fuertemente marcadas por el contexto más amplio de la difusión del paradigma. Ello afecta tanto las estrategias empresariales como las de los países.

iii) Por último, la selección entre el ingreso dependiente o el autónomo está determinada en alto grado por las condiciones de la empresa específica. Es preciso también conocer la evolución de las estructuras de poder, a fin de identificar claramente los intereses actuales y futuros de los posibles socios o competidores. Cuanto más débil sea el participante tanto más importante será que aprenda a bailar con los lobos poderosos (e incluso a distinguir entre lobos y descubrir cómo atraerlos).

Por supuesto, no todas las tecnologías están abiertas a la negociación. También puede ocurrir que sea necesario el enfrentamiento y se llegue a un juego de 


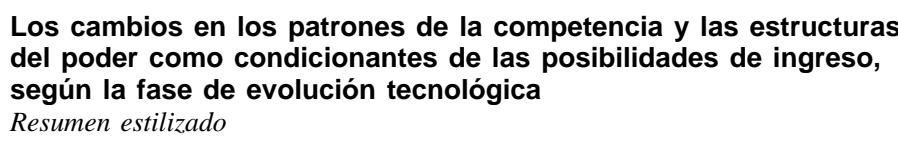

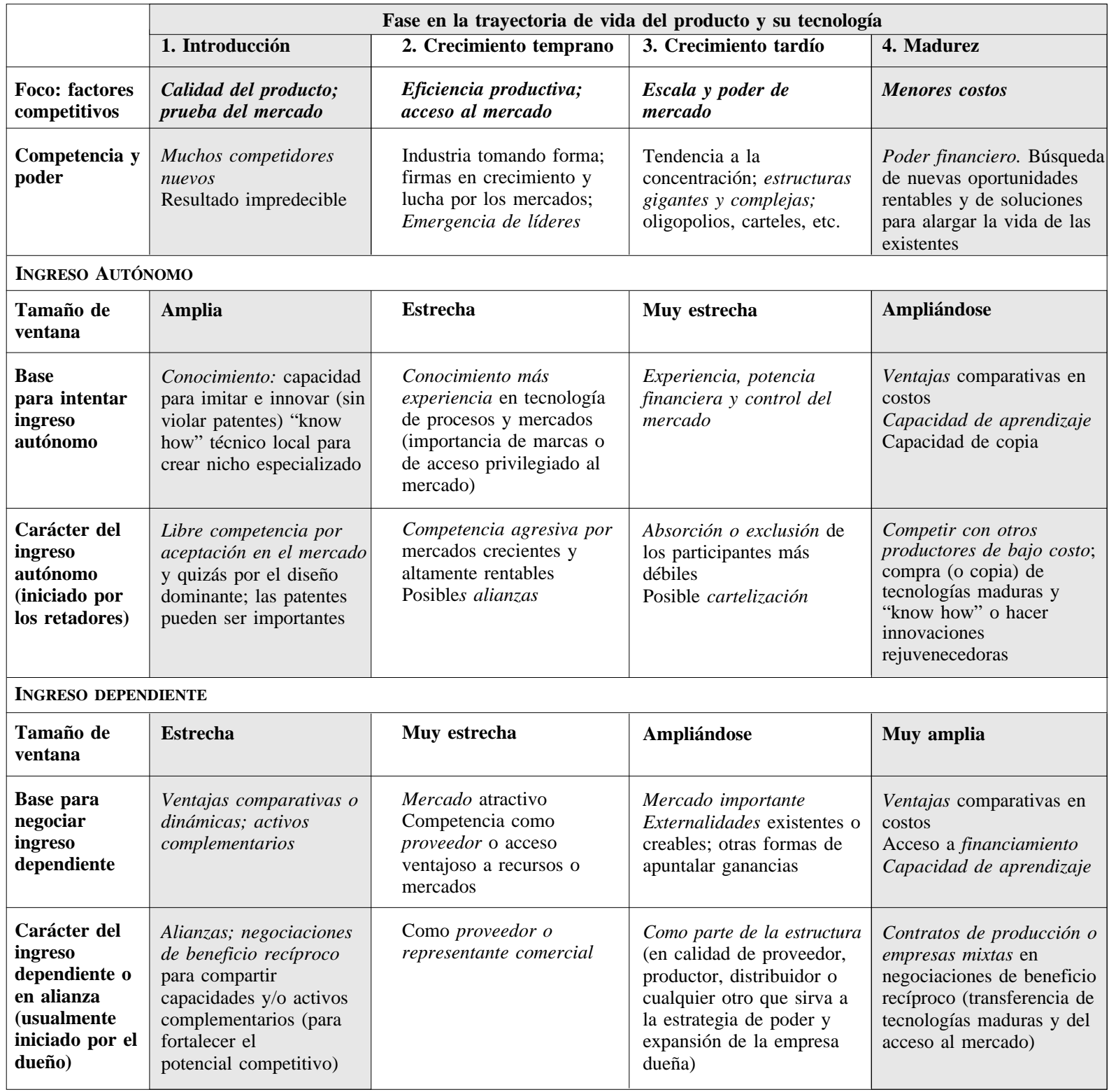

suma cero. Lo que sí hay que evitar es negociar acuerdos de beneficio mutuo como si fueran enfrentamientos. Es ingenuo creer que con las políticas de sustitución de importaciones o de promoción de exportaciones se les estaban imponiendo condiciones y restricciones a las empresas transnacionales o se les estaba obligando a establecerse en el país. En ambos casos se estaba negociando, en la práctica, un marco regulatorio y de incentivos que solucionaba al mismo tiempo los problemas de ambas partes. Esto indica que si se identifican los intereses y las necesidades de los posibles aliados en cada momento, se evita el peligro de apuntar al blanco equivocado y se negocia conociendo el valor de las propias ventajas competitivas. 
Históricamente, los procesos de crecimiento y desarrollo rápidos — ya sea que vengan adelantando desde atrás o llegando a las primeras filas — han sido fruto de procesos bien llevados de desarrollo tecnológico (Lall, 1992; Bell y Pavitt, 1993a; Reinert, 1994;
Freeman, 1994; Von Tunzelmann, 1995). En general, éstos se han basado en el establecimiento de juegos sucesivos de suma positiva con los más avanzados, y en la disposición de cambiar de juego según vayan evolucionando el contexto y las estructuras.

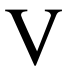

\section{La experiencia acumulada y las ventanas futuras de oportunidad}

Una mirada retrospectiva a la historia reciente del mundo en desarrollo y a las distintas estrategias aplicadas nos revela como, consciente o intuitivamente, se montaron sucesivos juegos de suma positiva entre el interés de las empresas de los países industrializados y el de los países en desarrollo. Un análisis de esta experiencia puede ayudar a mirar hacia el futuro con criterios mejor fundados. Sin embargo, como siempre sucede con las lecciones históricas, hay que distinguir entre lo recurrente y lo específico en cada caso. Hay patrones de cambio que se repiten en cada paradigma, pero cada uno es en esencia único en su género y debe analizarse en sus características singulares.

\section{Inventando y reinventando estrategias de de- sarrollo}

La era moderna de la intervención estatal deliberada en el proceso de industrialización de los países del tercer mundo se perfiló con claridad en el decenio de 1950, cuando un número creciente de industrias de producción en serie se hallaba en la fase tres, tratando de ampliar mercados, persiguiendo economías de escala, formando oligopolios y abriendo canales internacionales de comercialización. La industrialización por sustitución de importaciones, subvencionada por el Estado y protegida por barreras arancelarias, fue el juego de suma positiva establecido entonces. Las empresas internacionales multiplicaron lo que eran sus mercados de productos finales, exportando cantidades mucho mayores de partes a sus filiales en el exterior, las cuales, además, tenían mayores márgenes de beneficio. En los países en desarrollo, por su parte, aunque estas fábricas fueran sólo de "ensamblaje con destornillador”, se generó — tanto en ellas como en las empresas y organizaciones estimuladas por su demanda- un medio propicio para el aprendizaje del personal directivo y los trabajadores. Sus exigencias de servicios de construcción, carreteras, puertos, transporte, electricidad, agua y comunicaciones, estimularon la modernización del medio circundante y el desarrollo de muchas capacidades complementarias.

A mediados del decenio de 1960, algunos países comenzaron a enfrentar los límites del modelo de industrialización sustitutiva de importaciones, al tiempo que en los países adelantados muchos productos e industrias estaban alcanzando la fase cuatro, de madurez y agotamiento del dinamismo. Las políticas de transferencia de tecnología y promoción de exportaciones surgieron entonces como una nueva relación de beneficio mutuo. El proceso supuso la transferencia de tecnologías maduras a empresas públicas y privadas, así como la instalación de filiales de producción para la reexportación en lugares con mano de obra barata. Ya para el decenio de 1970, las empresas transnacionales estaban empeñadas en el proceso de redespliegue industrial, mediante el cual trasladaban una parte creciente de sus actividades productivas a países en desarrollo, generando así una corriente importante de exportaciones hacia los países adelantados. Los "milagros" del Brasil y la República de Corea y las zonas francas industriales de muchos países dieron la impresión de que estaba surgiendo un nuevo orden económico internacional. Se inició entonces el Diálogo Norte-Sur para negociar la concreción de esas esperanzas.

Al abrir el decenio de 1980 volvió a cambiar la situación. Muchos de los productos de la revolución microelectrónica, que había hecho irrupción a comienzos de los años setenta, estaban alcanzando la fase dos. Por otra parte, los japoneses habían revitalizado la industria automotriz y su nuevo paradigma de organización estaba transformando radicalmente a sus 
competidores en los Estados Unidos y Europa (Altshuler y otros, 1984). El fenómeno del estancamiento con inflación acompañó la llegada a la fase de madurez de la mayoría de las viejas industrias de los países avanzados; los mercados de exportación comenzaron a contraerse y se desencadenó la crisis de la deuda en el tercer mundo. Había que formular una nueva estrategia.

Sin embargo, la mayor parte de América Latina no lo hizo, y el resultado fue lo que acertadamente se llamó la década perdida. En cambio, los "cuatro tigres" de Asia dieron un salto adelante conquistando mercados desde la retaguardia y en los márgenes de las industrias revolucionarias de alto crecimiento. También revitalizaron las tecnologías maduras con prácticas modernas e ingresaron en las redes de empresas mundiales en calidad de proveedores de piezas y componentes como fabricantes de equipos de marca (OEM). Huelga subrayar el intenso proceso de aprendizaje y la importancia atribuida al capital humano y a la absorción activa de tecnología como factores explicativos de esos logros (Amsden,1989, cap.9; Bell y Pavitt,1993b), tan distintos de las prácticas más pasivas de transferencia tecnológica típicas de los países latinoamericanos y africanos, así como del resto de Asia durante ese período.
El gráfico 11 muestra cómo, desde los años cincuenta hasta ahora, se fueron adaptando las estrategias de desarrollo a las oportunidades creadas, por la maduración de un paradigma y el despliegue inicial del siguiente.

El decenio de 1990 se caracterizó por el desarrollo impetuoso de la nueva infraestructura de telecomunicaciones y su aplicación en la estructuración de las industrias emergentes y la modernización de las existentes. Al llegar una industria nueva tras otra a la fase dos comenzó una intensa competencia por posiciones en el mercado. Desde entonces fueron apareciendo variadas posibilidades para las empresas de los países en desarrollo, derivadas de un conjunto de nuevos fenómenos, como: la emergencia de las empresas y los mercados globalizados, las pugnas por imponer diseños dominantes y otras normas, la constitución de redes complejas de colaboración a escala mundial, el fortalecimiento del poder de las marcas registradas en el mercado, la búsqueda de ventajas, tanto dinámicas como estáticas, para la ubicación geográfica de las distintas actividades, el interés en adaptar los productos a determinados segmentos del mercado, la tendencia a la subcontratación externa (outsourcing) y otros comportamientos conexos. La calidad y la cantidad de oportunidades que de allí derivan han variado en

GRAFICO 11 Las oportunidades como un blanco móvil: Estrategias de desarrollo
cambiantes según las fases de despliegue de paradigmas sucesivos

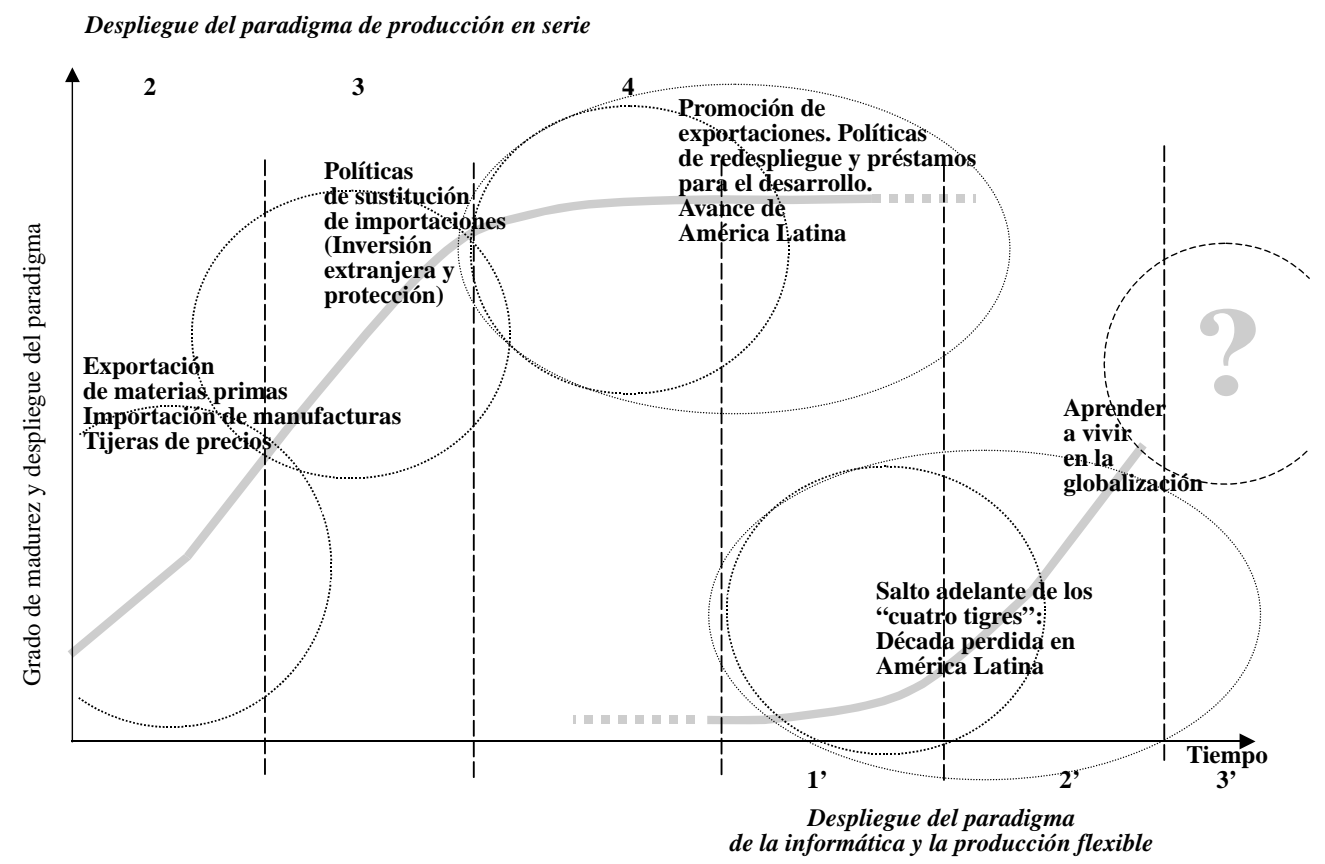

CAMBIO TECNOLOGICO Y OPORTUNIDADES DE DESARROLLO COMO BLANCO MOVIL • CARLOTA PEREZ 
función de las condiciones y la disposición de los diferentes agentes económicos y de los países donde operan.

La experimentación en los países en desarrollo ha sido muy diversa, tanto en los métodos como en los resultados: abarca desde los modernos contratos de maquiladoras y fabricación de equipo de marca (OEM) hasta las prácticas de las empresas asiáticas independientes y altamente competitivas, pasando por distintos tipos de empresas mixtas y alianzas (Hobday, 1994). También se ha registrado un gran crecimiento de los conglomerados locales interconectados en industrias específicas (como los programas de la India en materia de software), algunos de los cuales han alcanzado éxito en los mercados de exportación. En este período, los "cuatro tigres" asiáticos siguieron avanzando, estimulando la producción en otros países de Asia sudoriental y en China. En general, los países y empresas con estrategias exitosas han mostrado capacidad para aprender a vivir en la globalización.

Cada una de las estrategias sucesivas ha tenido ventajas y desventajas, beneficios y efectos negativos. Algunos países han avanzado a pasos agigantados, otros han dado pequeños pasos o no han logrado avanzar; algunos han conservado los beneficios obtenidos, otros los han perdido y han sufrido un retroceso. Algunos de los reveses pueden deberse al hecho de haberse aferrado a políticas que ya han dejado de ser eficaces. Hay que admitir que los resultados generales son desalentadores. Esto puede llevar al desencanto o bien al reconocimiento de la gran dificultad que supone reducir la brecha y de la necesidad de una mayor comprensión de la naturaleza de los problemas y las oportunidades.

\section{Cómo afrontar la próxima etapa}

Tarde o temprano en el nuevo siglo se crearán las condiciones para la plena realización del potencial de creación de riqueza que ofrece la era de la informática. El decenio de 1990 fue una etapa de experimentación en todas partes: dentro y fuera de las empresas globales, en los países, regiones, ciudades y localidades, en la economía, en los gobiernos y otras instituciones, y en los distintos niveles de la sociedad. En consecuencia, el sentido común del paradigma de redes flexibles se ha difundido ampliamente y se está convirtiendo en la manera normal de ver y hacer las cosas.

El comienzo del siglo XXI marca el paso hacia la tercera fase, o período de crecimiento tardío del actual paradigma. ${ }^{11}$ Muchas industrias están también alcanzando la fase tres de sus trayectorias, por lo cual buscan economías de escala y tienden a la oligopolización para moderar la libre competencia. Los acuerdos, las fusiones, las absorciones y otros arreglos están dando lugar a la concentración mundial de muchas industrias importantes en unas pocas megaempresas o grandes alianzas globales. ${ }^{12}$ Más aun, el creciente poder de la intermediación, gracias a su control del acceso a la clientela, podría llevar a una versión moderna de las antiguas compañías mundiales de comercio (trading companies), basada ahora en el poder de la informática y las telecomunicaciones. ${ }^{13}$ Estas empresas gigantescas podrían convertirse en inmensos "paraguas" globales que abarcaran toda la diversidad mundial en su especialidad y todos los segmentos — desde los nichos más especializados o suntuarios hasta los productos o servicios más estandarizados y más baratos-, comprando y vendiendo a lo largo y ancho del planeta y ubicando cada actividad allí donde encuentre mayores ventajas.

Para el mundo en desarrollo, la próxima etapa puede ser un período muy complejo de acomodación a las nuevas estructuras emergentes de poder. Para las empresas, las localidades, las regiones y los países, el descubrir qué tipos de juegos de suma positiva son posibles con estos gigantes puede definir la naturaleza de la próxima ventana de oportunidad. Tratar de crear redes locales o regionales, ya sea independientes o en conexión con las redes globales, podría aun ser posible cuando existan ventajas locales muy específicas. Por supuesto, los países y las empresas que han adquirido capacidad tecnológica y de organización, comercialización y negociación estarán en condiciones mucho mejores ya sea para encontrar un acomodo favorable bajo los "paraguas" globales o para ubicarse audazmente fuera de ellos. La cooperación entre empresas, regiones o países puede aumentar el poder de negociación de los protagonistas y agentes, tanto los fuertes como los débiles.

La formulación de estrategias exitosas exige, por lo tanto, evaluar las condiciones y la capacidad acumulada en el país, la región, la empresa o la red en

\footnotetext{
${ }^{11}$ Para un análisis más completo de las fases en el despliegue de un paradigma y el papel que cumple el capital financiero en el proceso, véase Pérez (por publicarse 2002).

12 Véanse Chesnais (1988 y 1992), Bressand (1990), Klepper y Kenneth (1994) y Castells (1997).

${ }^{13}$ Véanse Bressand y Kalypso, eds. (1989) y Kanellou (2000).
} 
cuestión, a fin de aprovechar la próxima ventana de oportunidad (no la que ya se está cerrando), al tiempo que se reconocen, adoptan y adaptan el potencial y las características del paradigma pertinente. A continuación se examinan algunas de las implicaciones de estas características.

\section{VI}

\section{Cómo abordar el desarrollo en el contexto del paradigma actual}

El crecimiento acelerado de empresas, localidades y países depende de la disponibilidad de un amplio potencial tecnológico y una forma de organización adecuada para aprovecharlo. Cualquiera sea el punto de partida y el objetivo que se persiga, es probable que en la época actual el éxito dependa de cuán profundamente se asimile la lógica del nuevo paradigma y cuán creativamente se le adopte y adapte en todos los niveles de la sociedad.

Las viejas pirámides centralizadas de la producción en serie atendían eficazmente las necesidades de empresas y gobiernos, universidades, hospitales y organizaciones privadas y públicas de toda índole. Desde hace más de veinte años, las empresas modernas, ya sean internacionales o locales, se han estado reestructurando a fondo y han comprendido rápidamente las ventajas de las redes y de las organizaciones que aprenden. ${ }^{14}$ Para los gobiernos ha llegado el momento de experimentar en la misma dirección.

\section{La tecnología al centro de las estrategias de desarrollo}

Es un hecho ampliamente reconocido que el crecimiento de la economía japonesa, hasta constituirse en la segunda economía del mundo (y mantenerse allí a pesar de su crisis) entrañó un proceso de prospectiva tecnológica encaminado a determinar colectivamente el camino que debía seguirse, así como intensas actividades de aprendizaje, capacitación e innovación (Peck y Goto, 1981; Irvine y Martin, 1985). El avance de los "cuatro tigres" de Asia desde la retaguardia también supuso una labor de educación y aprendizaje en gran escala (Ernst, Ganiatsos y Mytelka, eds., 1998).

14 Nonaka (1994), Senge (1990) y Lundvall (1997); véase también el sitio web del proyecto DRUID (DRUID, 2001).
Además, las empresas globales que han tenido éxito han reformulado sus estructuras y prácticas para promover un continuo proceso de aprendizaje y mejoramiento. La gestión del conocimiento (Nonaka,1995; Burton-Jones, 1999; Lamoreaux y otros, eds., 1999) se está convirtiendo en una preocupación fundamental: las empresas no sólo organizan cursos regulares de capacitación a todo nivel, sino que algunas también han creado sus propias "universidades" (Wiggenhorn, 1990).

En los países en desarrollo, es una ilusión creer que puedan lograrse avances significativos sin esfuerzos equivalentes. No hay fórmulas mágicas para lograr el desarrollo sin dominio tecnológico, entendido en el sentido elemental de incorporar en personas el necesario “know-how" social, técnico y económico. Esta realidad, plenamente reconocida en el pasado, se perdió de vista en las peculiares condiciones de las políticas de sustitución de importaciones. Estas permitieron, durante un período, que muchos países lograran extraordinarios resultados en materia de crecimiento, invirtiendo en instalaciones, equipos y tecnologías maduras, sin tener que hacer esfuerzos intensos de aprendizaje y capacitación.

En este nuevo paradigma, en particular, cobra mayor importancia que nunca el desarrollo de la capacidad para aprovechar la información y el conocimiento en aras de la innovación. Tal vez el sentido más provechoso de la expresión "sociedad del conocimiento" (Castells, 1997; Mansell y Wehn, eds., 1998) sea el de la creación de condiciones para que todos los miembros de la sociedad tengan acceso a la información y la utilicen. Por consiguiente, el fortalecimiento de la capacidad de aprendizaje individual y social para generar riqueza constituye un modo fundamental de aumentar el potencial de desarrollo.

Por ello, la tecnología debe ocupar un lugar central, y no periférico, en las políticas de desarrollo. En 
la práctica, esto significa una manera diferente de concebir estrategias, y exige una reformulación completa tanto de los sistemas de educación y capacitación como de las políticas de ciencia y tecnología.

En la reforma educativa es preciso actualizar y mejorar la calidad de los programas técnicos y, lo que es quizás más importante, transformar radicalmente los métodos, los objetivos y los instrumentos de la enseñanza para hacerlos relevantes para el futuro y compatibles con las nuevas formas de organización (Pérez, 1991 y 2000; CEPAL, 1992) Esa reforma debe inducir a los estudiantes a hacerse responsables de sus propios procesos de formación; debe poner el acento en el proceso de "aprender a aprender" y de "aprender a cambiar"; debe fomentar la labor creadora en equipo, aprendiendo a articular problemas y a evaluar soluciones alternativas; debe encontrar los medios para brindar acceso a Internet y al mundo de la informática; y debe crear las condiciones necesarias para dotar a los estudiantes, no tanto de capacidad de respuesta cuanto de "capacidad de pregunta" y de habilidad para procesar información.

Estos conocimientos y aptitudes se están transformando en las condiciones básicas para participar en el lugar de trabajo moderno, donde las empresas enfrentan un entorno en constante evolución que exige el mejoramiento continuo. También permiten a las personas y a los grupos ser responsables de su propia capacidad para generar riqueza, ya sea en calidad de empleados o como empresarios, y proporcionan la capacidad organizativa necesaria para mejorar sus comunidades y organizaciones, bien sea en calidad de miembros activos o como dirigentes.

La otra transformación vital se refiere al sistema de ciencia y tecnología, establecido en la mayoría de los países en desarrollo como un conjunto de instituciones gubernamentales encargadas del desarrollo tecnológico. La experiencia demostró que el aprovechamiento de esa capacidad para incorporar innovaciones al mundo de la producción fue muy escaso. Como la mayoría de las industrias utilizaba tecnologías ya maduras, éstas tenían poca capacidad para absorber los resultados de estos tecnólogos de laboratorio. La consiguiente frustración al tratar de "tender el puente" universidad-industria llevó a la mayoría de los investigadores tecnológicos a convertirse en apéndices de la comunidad científica y a adoptar sus métodos, sus escalas temporales, sus valores y sus actitudes.

En el nuevo contexto, es necesario actuar en dos direcciones: invertir considerablemente en la investigación para el futuro y reconectar el esfuerzo de desa- rrollo tecnológico con el mejoramiento directo e inmediato de las redes de producción y de la calidad de la vida.

Esta transición de un sistema de ciencia y tecnología impulsado por la oferta a una red interactiva con los productores se ha denominado "sistema nacional de innovación" (SNI) (Freeman, 1993; Lundvall, 1988) y definido como "la red de instituciones de los sectores público y privado cuyas actividades e interacciones inician, importan, modifican y difunden nuevas tecnologías" (Freeman, 1995).

Se parte del supuesto de que el sistema nacional de innovación es una creación social y no gubernamental. Incluye el entorno en donde se estimula y apoya la innovación; la calidad de los vínculos entre los proveedores, productores y usuarios; el sistema de educación y capacitación; distintas organizaciones públicas y privadas que facilitan el cambio técnico; las leyes, los reglamentos e incluso las ideas y actitudes hacia la tecnología y el cambio (Arocena, 1997).

\section{Reinventar el Estado "fuerte"15}

A estas alturas se hace evidente que la dicotomía mercado vs. Estado es inadecuada para abordar los problemas concretos que se examinan en el presente trabajo. Se necesitan tanto los mercados como el Estado, aunque redefinidos y combinados de una nueva manera. En cualquier caso, se desprende del análisis que una estrategia exitosa de desarrollo para un país rezagado, según la lógica del paradigma actualmente en difusión - y especialmente en presencia de las megaempresas globales- exigirá una gran cooperación entre las empresas locales y entre éstas y el Estado a distintos niveles.

Aunque la magnitud y la complejidad de la tarea requieren un Estado fuerte, lo que fue el omnipotente Estado nacional, desarrollado después de la Segunda Guerra Mundial, ha de ser redefinido y reinventado, probablemente siguiendo directrices similares a las aplicadas por las empresas globales modernas.

Nadie sería capaz de sostener que la máxima gerencia de una empresa gigantesca se debilita al descentralizar funciones y otorgar una gran autonomía y poder decisorio a sus directores de productos, fábricas o mercados en todo el mundo. Las computadoras y las telecomunicaciones facilitan el ejercicio efectivo de un liderazgo firme sobre una vasta y creciente estructura

${ }^{15}$ Véanse Reinert (1999), Wade (1990) y Osborne y Gaebler (1994). 
integrada por componentes semiautónomos, mediante el seguimiento de directrices estratégicas. Gracias a los canales interactivos de información, es posible supervisar y controlar redes sumamente complejas con componentes flexibles y fuertemente diferenciados.

Esas redes pueden ser imitadas en la nueva configuración del sector público fuerte que se necesita. Como en las revoluciones tecnológicas anteriores, una vez que la tecnología ayuda a definir la configuración óptima de las organizaciones, éstas pueden funcionar eficazmente, incluso sin la tecnología. Ello a su vez permite sentar las bases para la incorporación de la tecnología moderna, cuando sea necesario.

El Estado nacional central puede ejercer su función de liderazgo orientando las actividades de los distintos agentes sociales para que converjan en una dirección general de cambio convenida de común acuerdo. También puede desempeñar un papel fundamental como intermediario entre actores e instituciones emergentes a nivel global o suprarregional y los agentes regionales, locales e incluso municipales o parroquiales, cuya autonomía tiende a ser cada vez mayor.

Se está produciendo también un proceso de difusión del poder (Strange, 1996). Las redes de intereses privados, los distintos componentes de la sociedad civil, las empresas globales, los medios de comunicación, los grupos de interés organizados, las organizaciones no gubernamentales (ONG) y otras entidades están aumentando la diversidad de los agentes del desarrollo y sus interconexiones, tanto en el plano nacional como en el mundial. El Estado nacional debe ser capaz de actuar como intermediario dentro del país y entre los diversos niveles supranacionales y subnacionales a fin de promover y negociar oportunidades equitativas para todos. Asumiendo el papel de promotor del consenso entre los distintos protagonistas, es posible que el Estado logre ejercer una autoridad más eficaz, como base para establecer un poder real que le permita influir en el curso de los acontecimientos.

\section{Pensar globalmente, actuar localmente}

En nuestra opinión, el nuevo asiento del Estado desarrollista dinámico es la administración local. Es preciso reconsiderar la idea del plan central promotor de un grupo de industrias nacionales que genere la riqueza necesaria para financiar el progreso social. En cada país ciertamente habrá que desarrollar industrias remolcadoras de la economía, es decir, un conjunto de actividades productivas importantes y competitivas, estrecha- mente vinculadas con los mercados globales, que se mantengan en la frontera tecnológica y sean capaces de propulsar el crecimiento y producir las divisas necesarias. Pero eso no basta. Ya es hora -y las condiciones son propicias para ello- de abandonar la ilusión del efecto de goteo y avanzar hacia la participación directa de toda la población en actividades generadoras de riqueza.

Las características del paradigma actual hacen posible vislumbrar una modalidad de desarrollo más integrado, donde las grandes industrias competitivas que salen al mercado mundial se complementan con el desarrollo diferenciado de cada parte del territorio. Ello es posible aprovechando la nueva flexibilidad en cuanto a variedad de productos y escalas de producción competitivas, su poder para aumentar la calidad y eficiencia de todos los sectores y actividades, incluso las artesanales, y, lo que es más importante, el hecho de que todos los seres humanos tengan acceso a los procesos de aprendizaje continuo para mejorar constantemente sus capacidades, su trabajo y su ambiente.

Pueden citarse muchos ejemplos de gobiernos locales que descubren la vocación productiva de la comunidad, promueven el consenso y recaban la participación de empresas, bancos, el sistema educativo y otros agentes locales y externos para impulsar proyectos de desarrollo (Tendler, 1997; Gabor, 1991; The Illinois Coalition, 1999) También existen redes locales de empresas pequeñas y medianas que colaboran en el desarrollo de los negocios y la tecnología para cubrir juntas los mercados de exportación (Nadvi y Schmitz, eds., 1999). Los estudiosos de la interacción en el seno de estos "clusters" (o aglomeraciones de empresas afines en una localidad) han sugerido utilizar la expresión "sistemas locales de innovación" (Cassiolato y Lastres, eds., 1999) aunque a nuestro juicio sería más sugerente llamarlos "redes territoriales de innovación".

También existe la experiencia altamente satisfactoria de los bancos especializados que otorgan micropréstamos para ayudar a pobladores de las zonas urbanas y rurales desfavorecidas a poner en marcha actividades generadoras de ingreso (Otero y Rhyne, eds., 1994; Chaves y González, 1996). Gradualmente está desapareciendo así el mito de que los puestos de trabajo son la única manera de mejorar la calidad de vida de poblaciones enteras, en un momento en que se avanza hacia formas múltiples de capacidad empresarial individual y colectiva. A fin de mejorar la difícil situación de las comunidades rurales, es necesario abandonar los tradicionales sesgos 
a favor de lo urbano y lo industrial (Fieldhouse 1986, p. 152 y Mytelka 1989), para dotar a las administraciones locales de los recursos y el apoyo técnico que les permitan abordar directamente la cuestión del mejoramiento del nivel de vida local. Ello no excluye que el resultado de estos esfuerzos pueda llevar a la localidad a convertirse en proveedora de empresas globales o a formar parte de las redes de apoyo de las actividades de exportación importantes del país.

\section{Modernidad y valores}

Naturalmente se trata de decisiones políticas, pero las opciones reales no siempre son claras. Históricamente, en cada transición de un paradigma a otro se vuelven borrosas las definiciones corrientes de izquierda y derecha. Cada uno de los grupos experimenta una división interna entre quienes se aferran a antiguas formas de alcanzar sus objetivos y quienes aprovechan el potencial del nuevo paradigma y lo orientan hacia sus fines (gráfico 12).

En la transición anterior, entre las dos guerras mundiales, el carácter social y homogeneizador del nuevo paradigma de la producción en serie era tan fuerte que incluso el nazismo se autodenominó nacional-socialismo. De la misma manera, el papel que desempeñaba el Estado centralizado era tan importante que, después de la Segunda Guerra Mundial, se adoptó íntegramente, incluso en las naciones más liberales, el modelo de intervención estatal en la economía, siguiendo las ideas keynesianas — que habían en-

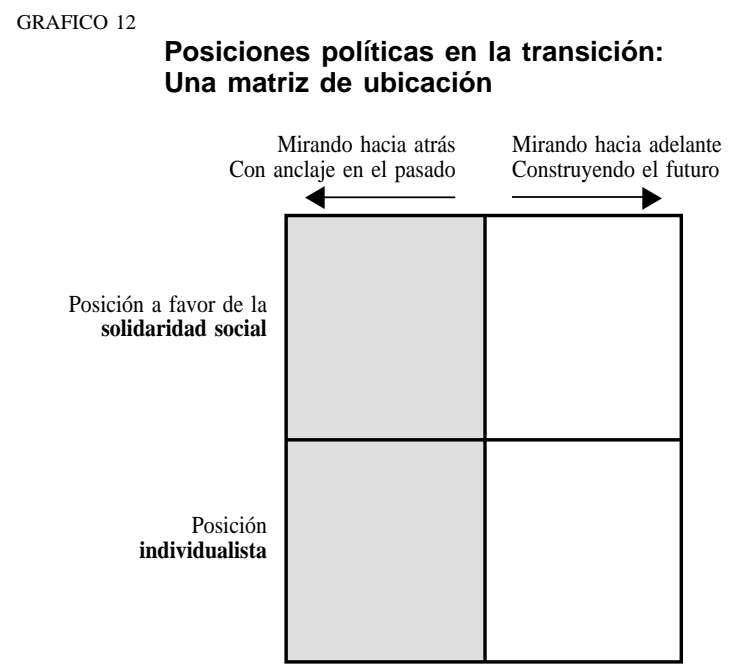

contrado tanta resistencia en los decenios de 1920 y 1930 - Lamentablemente, para quienes están convencidos de la necesidad de la solidaridad social, el neoliberalismo es el único programa coherente que ha adoptado el actual paradigma. Aunque existen miles de experimentos aislados de prácticas orientadas hacia el futuro, como la democracia participativa y la creación de consenso local, todavía no se ha presentado una experiencia o propuesta coherente que pueda servir como alternativa moderna al mercado puro. A nuestro juicio, sin esa alternativa, la economía mundial puede crecer, pero probablemente haya pocas esperanzas de un auge generalizado del desarrollo.
Abernathy, W. y J. Utterback (1975): A dynamic model of process and product innovation, Omega, vol. $3, \mathrm{~N}^{\circ} 6$.

Abramovitz, M. (1986): Catching up, forging ahead and falling behind, Journal of Economic History, $\mathrm{N}^{\mathrm{o}} 46$.

Altshuler, A. y otros (1984): The Future of the Automobile: The Report of MIT's International Automobile Program, Cambridge, Massachusetts, The MIT Press.

Amsden, A. (1989): Asia's Next Giant. South Korea and Late Industrialization, Oxford, Reino Unido, Oxford University Press.

Arocena, R. (1997): Qué piensa la gente de la innovación, la competitividad, la ciencia y el futuro, Montevideo, Trilce.

Arthur, W. B. (1989): Competing technologies increasing returns and lock-in by historical events, The Economic Journal, vol. 99, $\mathrm{N}^{\circ} 394$, Oxford, Reino Unido, Basil Blackwell. Reproducido en Freeman (ed.), 1990

Bell, M. y K. Pavitt (1993a): Technological accumulation and industrial growth: contrasts between developed and developing countries, Industrial and Corporate Change, vol. 2, $\mathrm{N}^{\circ} 2$, Oxford, Reino Unido, Oxford University Press.
Bell, M. y K. Pavitt (1993b): Accumulating technological capability in developing countries, Proceedings of the World Bank Annual Conference on Development Economics. Washington, D.C., Banco Mundial.

Bressand, A. (1990): Electronics cartels in the making?, Transatlantic Perspectives, $\mathrm{N}^{\circ} 21$.

Bressand, A. y N. Kalypso (eds.) (1989): Strategic Trends in Services: An Inquiry into the Global Service Economy, Nueva York, Harper y Row.

Burton-Jones, A. (1999): Knowledge Capitalism: Business, Work and Learning in the New Economy, Oxford, Reino Unido, Oxford University Press.

Cassiolato, J. y H. Lastres (eds.) (1999): Globalizaçâo \& inovaçâo localizada. Experiencias de sistemas locais no Mercosul, Brasilia, Instituto Brasilero de Información en Ciencia y Tecnología (IBICT).

Castells, M. (1997): La era de la información. Economía, sociedad y cultura, vol. 1, La era de la información: la sociedad red, vol. 1, Madrid, Alianza Editorial. 
CEPAL (Comisión Económica para América Latina y el Caribe) (1990): Transformación productiva con equidad, LC/G.1601P, Santiago de Chile. Publicación de las Naciones Unidas, número de venta S.90.II.G.6.

(1992): Educación y conocimiento: eje de la transformación productiva con equidad, LC/G.1702/Rev.2-P, Santiago de Chile.

Chaves, R. y C. González (1996): The design of successful rural financial intermediaries: Evidence from Indonesia, World Development, vol. 24, № 1, Oxford, Reino Unido, Pergamon Press Ltd.

Chesnais, F. (1988): Multinational enterprises and the international diffusion of technology, G. Dosi y otros (eds.), Technical Change and Economic Theory, Londres, Pinter Publishers.

(1992): National systems of innovation, foreign direct investment and the operations of multinational enterprises, B. Lundvall, National Systems of Innovation: Towards a Theory of Innovation and Interactive Learning, Londres, Pinter Publishers.

Coombs, R., P. Saviotti y V. Walsh (1987): Economics and Technological Change, Londres, Macmillan Educational, Ltd.

Coriat, B. (1991): Penser à l'envers, Paris, Christian Bourgeois Editeur.

Cundiff, E. y otros (1973): Fundamentals of Modern Marketing, Englewood Cliffs, New Jersey, Prentice-Hall.

David, P. (1985): Clio and the Economics of QWERTY, The American Economic Review, vol. 75, No 2, Nashville, Tennessee, American Economic Association. Reproducido en Freeman (ed.), The Economics of Innovation, Aldershot, Reino Unido, Edward Elgar Publishing, 1990.

Dosi, G. (1982): Technological paradigms and technological trajectories. A suggested interpretation of determinants and directions of technical change, Research Policy, vol. II, $\mathrm{N}^{\circ} 3$, Amsterdam, Países Bajos, North Holland.

(1988): Sources, procedures, and macroeconomic effects of innovation, Journal of Economic Literature, vol. XXVI, $\mathrm{N}^{\circ}$ 3, Nashville, Tennessee, American Economic Association. Reproducido en Freeman (ed.), 1990.

Dosi, G. (ed.) (1988): Technical Change and Economic Theory, Londres, Pinter Publishers.

DRUID (Danish Research Unit on Industrial Dynamics) (2001): A-The Firm as a Learning Organization. http://www.business.auc.dk/ druid

Ernst, D., T. Ganiatsos y L. Mytelka (eds.) (1998): Technological Capabilities and Export Success in Asia, Londres, Routledge.

Fagerberg, J. y otros (eds.) (1994): The Dynamics of Technology, Trade and Growth, Aldershot, Reino Unido, Edward Elgar.

Fieldhouse, D. (1986): Economic Decolonisation and Arrested Development, Londres, George Allen.

Freeman, C. (1974): The Economics of Industrial Innovation, Harmondsworth, Middlesex, Reino Unido, Penguin Books Ltd. (1993): La experiencia de Japón: el reto de la innovación, Caracas, Editorial Galac.

(1994): Technological revolutions and catching up: ICT and the NICs, J. Fagerberg y otros (eds.), The Dynamics of Technology, Trade and Growth, Aldershot, Reino Unido, Edward Elgar.

(1995): The national system of innovation in historical perspective, Cambridge Journal of Economics, vol. 19, $\mathrm{N}^{\mathrm{o}} 1$, Cambridge, Reino Unido, Academic Press Limited.

Freeman, C. (ed.) (1990): The Economics of Innovation, Aldershot, Reino Unido, Edward Elgar Publishing

Freeman, C., J. Clark y L. Soete (1982): Unemployment and Technical Innovation. A Study of Long Waves and Economic Development, Londres, Frances Pinter Publishers.
Freeman, C. y F. Louçã (2001): As Time Goes By: From the Industrial Revolutions to the Information Revolution, Oxford, Reino Unido, Oxford University Press.

Freeman, C. y C. Pérez (1988): Structural crises of adjustment: Business cycles and investment behaviour, G. Dosi y otros (ed.), Technical Change and Economic Theory, Londres, Pinter Publishers. $3^{\mathrm{a}}$ edición, Londres,

Freeman, C. y L. Soete (1997): The Economics of Industrial Innovation, Pinter Publishers.

Gabor, A. (1991): Rochester focuses: A community's core competence, Harvard Business Review, Boulder, Colorado, Harvard University, julio-agosto.

Gerschenkron, A. (1962): Economic Backwardness in Historical Perspective, Cambridge, Massachusetts, Harvard University Press.

Grübler, A. (1990): The Rise and Fall of Infrastructures. Dynamics of Evolution and Technological Change in Transport, Heidelberg, Physica-Verlag.

Hirsch, S. (1965): The United States electronic industry in international trade, National Institute Economic Review, $\mathrm{N}^{\mathrm{o}} 34$.

(1967): Location of Industry and International Competitiveness, Oxford, Reino Unido, Clarendon Press.

Hobday, M. (1994): Export-led technology development in the Four Dragons: The case of electronics, Development and Change, vol. 25, No 2, La Haya, Países Bajos, Institute of Social Studies.

(1995): Innovation in East Asia: The Challenge to Japan, Aldershot, Reino Unido, Edward Elgar.

Hoffman, K. y H. Rush (1988): Microelectronics and the Clothing Industry, Nueva York, Praeger.

IDS Collective Efficiency Research Project (2001): http://www.ids.ac.uk/ ids/global/coleff.html

Irvine, J. y B. Martin (1985): Foresight in Science Policy: Picking the Winners, Londres, Pinter.

Jang-Sup, S. (1992): Catching up and technological progress in lateindustrializing countries, Cambridge, Massachusetts, Cambridge University, tesis de maestría.

Kanellou, D. (2000): The new role of intermediaries in travel and tourism distribution channels IPTS (Institute for Prospective Technology Studies), № 48, pp.12-22, Comisión Europea, Sevilla, España.

Katz, J. (ed.) (1996): Estabilización macroeconómica, reforma estructural y comportamiento industrial; estructura y funcionamiento del sector manufacturero latinoamericano en los años 90, Buenos Aires, Alianza Editorial.

Klepper, S. y S. Kenneth (1994): Technological change and industry shakeouts, trabajo presentado en la Quinta Conferencia de la Sociedad Internacional, Joseph A. Schumpeter, Münster, agosto.

Kotler, P. (1980): Principles of Marketing, Englewood Cliffs, New Jersey, Prentice-Hall.

Lall, S. (1992): Technological capabilities and industrialization, World Development, vol. 20, $\mathrm{N}^{\circ}$ 2, Oxford, Reino Unido, Pergamon Press.

Lamoreaux, N. y otros (eds.) (1999): Learning by Doing in Markets, Firms and Countries, Cambridge, Massachusetts, Oficina Nacional de Investigaciones Económicas.

Leontief, W. (1954): Domestic production and foreign trade: The American capital position re-examined, Economia internazionale, vol. 7, № 1, Génova, Italia, Istituto di Economia Internazionale.

Lundvall, B. (1988): Innovation as an interactive process: From userproducer interaction to the national system of innovation, $\mathrm{G}$. Dosi y otros (ed.), Technical Change and Economic Theory, Londres, Pinter Publishers.

(1992): National Systems of Innovation: Towards a Theory of Innovation and Interactive Learning, Londres, Pinter Publishers. 
(1997): Information technology in the learning economy: Challenges for development strategies, Communications \& Strategies, $\mathrm{N}^{\mathrm{o}} 28$.

Mansell, R. y U. Wehn (eds.) (1998): Knowledge Societies: Information Technology for Sustainable Development, Oxford, Reino Unido, Oxford University Press.

Mytelka, L. (1989): The unfulfilled promise of African industrialization, African Studies Review, vol. 32, No 3 .

(1991): New models of competition in the textile and clothing industry: Some consequences for third world exporters, J. Niosi (ed.), Technology and National Competitiveness, Montreal, Canadá, McGill-Queen's University Press.

(1994): Dancing with wolves: Global oligopolies and strategic partnerships, J. Hagedoorn (ed.), Technical Change and the World Economy. Convergence and Divergence in Technology Strategies, Aldershot, Reino Unido, Edward Elgar.

Nadvi, K. (1999): The cutting edge: collective efficiency and international competitiveness in Pakistan, Oxford Development Studies, vol. 27, $\mathrm{N}^{\mathrm{o}} 1$.

Nadvi, K. y H. Schmitz (eds.) (1999): Industrial clusters in developing countries, World Development, vol. 27, número especial, Oxford, Reino Unido, Pergamon Press, Ltd.

Nelson, R. y Winter S. (1977): In search of a useful theory of innovation, Research Policy, vol. 6, $\mathrm{N}^{\circ} 1$, pp. 36-76.

Nonaka, I. (1994): Dynamic theory of organizational knowledge creation, Organizational Sciences, vol. 5, $\mathrm{N}^{\circ} 1$, febrero.

(1995): The knowledge-creating company: How Japanese companies create the dynamics of innovation, Harvard Business Review, Boulder, Colorado, Harvard University, noviembre-diciembre.

Osborne, D. y T. Gaebler (1994): La reinvención del gobierno. La influencia del espíritu empresarial en el sector público, Madrid, Paidós.

Otero, M. y E. Rhyne (eds.) (1994): The New World of Microenterprise Finance. Building Healthy Financial Institutions for the Poor, West Hartford, Connecticut, Kumarian Press.

Peck, J. y A. Goto (1981): Technological and economic growth: The case of Japan, Research Policy, vol. 10, Amsterdam, Países Bajos, Elsevier Science Publishers, B.V.

Pérez, C. (1983): Structural change and the assimilation of new technologies in the economic and social systems, Futures, vol. 15, N ${ }^{\circ}$, Surrey, Reino Unido, IPC Science and Technology Press UK.

(1985): Microelectronics, long waves and world structural change: New perspectives for developing countries, World Development, vol. 13, № 3, Oxford, Reino Unido, Pergamon Press, Ltd.

(1986): Las nuevas tecnologías: una visión de conjunto, C. Ominami (ed.), El sistema internacional y América Latina. La tercera revolución industrial: impactos internacionales del actual viraje tecnológico, Buenos Aires, Grupo Editor Latinoamericano.

(1991): Nuevo patrón tecnológico y educación superior: una aproximación desde la empresa, en G. López Ospina (ed.), Retos científicos y tecnológicos, Caracas, Organización de las Naciones Unidas para la Educación, la Ciencia y la Cultura (UNESCO).

(1996): La modernización industrial en América Latina y la herencia de la sustitución de importaciones, Comercio exterior, vol. 46, № 5, México, D.F., Banco Nacional de Comercio Exterior, S.N.C.
(2000): La reforma educativa ante el cambio de paradig$m a$, Caracas, UCAB-Eureka.

- (por publicarse 2002): Technological Revolutions and Finance Capital: The Dynamics of Bubbles and Golden Ages, Cheltenham, Reino Unido, Edward Elgar.

Pérez, C. y L. Soete (1988): Catching up in technology: Entry barriers and windows of opportunity, G. Dosi y otros (ed.), Technical Change and Economic Theory, Londres, Pinter Publishers.

Peters, T. (1989): Thriving on Chaos: Handbook for a Management Revolution, Londres, MacMillan.

Porter, M.E. (1991): La ventaja competitiva de las naciones, Buenos Aires, J. Vergara Editor, S.A.

Radosevic, S. (1999): International Technology Transfer and Catchup in Economic Development, Massachusetts, Edward Elgar Publishing.

Reinert, E. (1994): Catching-up from way behind. A third world perspective on first world history, J. Fagerberg y otros (eds.), The Dynamics of Technology, Trade and Growth, Aldershot, Reino Unido, Edward Elgar.

(1999): The role of the state in economic growth, Journal of Economic Studies, vol. 26, N ${ }^{\circ}$ 4-5, West Yorkshire, Reino Unido, MCB University Press Ltd.

Sahal, D. (1985): Technological guideposts and innovation avenues, Research Policy, vol. 14, No 2, Amsterdam, Países Bajos, North Holland.

Schmitz, H. y P. Knorringa (1999): Learning from Global Buyers, IDS working paper, $N^{\circ} 100$, Sussex, Reino Unido, Universidad de Sussex, Instituto de Estudios para el Desarrollo.

Schmitz, H. y K. Nadvi (1999): Clustering and industrialization: Introduction, World Development, vol. 27, № 9, Oxford, Reino Unido, Pergamon Press Ltd.

Senge, P. (1990): La quinta disciplina, Barcelona, Granica.

Strange, S. (1996): The Retreat of The State. The Diffusion of Power in The World Economy, Cambridge, Reino Unido, Cambridge University Press.

Tendler, J. (1997): Good Government in the Tropics, Baltimore, Pennsylvania, The Johns Hopkins University Press.

The Illinois Coalition (1999): Technology and Jobs Agenda. A Vision and Plan for Technology-Based Economic Development in Illinois. www.ilcoalition.org/tja.htm

Vernon, R. (1966): International investment and international trade in the product cycle, Quarterly Journal of Economics, vol. 80, Cambridge, Massachusetts, Harvard University, mayo.

Von Tunzelmann, G. (1995): Technology and Industrial Progress. The Foundations of Economic Growth, Aldershot, Reino Unido, Edward Elgar.

Von Tunzelmann, N. y E. Anderson (1999): Technologies and skills in long-run perspective, Sussex, Reino Unido, Universidad de Sussex, mimeo.

Wade, R. (1990): Governing the Market: Economic Theory of Government in East Asia Industrialization, Princeton, New Jersey, Princeton University Press.

Wells, L. (1972): International trade: The product life cycle approach, en L. Wells (ed.), The Product Life Cycle and International Trade, Boston, Harvard University, Graduate School of Business Administration, Division of Research.

Wiggenhorn, W. (1990): Motorola U: When training becomes an education, Harvard Business Review, vol. 68, No 4, Boulder, Colorado, Harvard University, julio-agosto.

Wolf, J. (1912): Die Volkswirtschaft der Gegenwart und Zukunft, A. Deichertsche Verlags-buchandlung. 